\title{
LAS VÍAS DE RESPONSABILIDAD DE LAS EMPRESAS MULTINACIONALES POR DAÑOS AMBIENTALES. EI CASO DUTCH SHELL NIGERIA*
}

DANIEL IGLESIAS MÁRQUEZ

\author{
Becario predoctoral del Pprograma de Formación de Profesorado Universitario (FPU) \\ Universitat Rovira $i$ Virgili \\ daniel.iglesias@urv.cat
}

\section{StePHANIE V. Ascencio SeRrato \\ Estudiante predoctoral \\ Universitat Rovira i Virgili \\ fannyascencio@gmail.com}

Recibido: 12 de marzo de 2014 / Aceptado: 21 de mayo de 2014

RESUMEN: La presente nota tiene como objetivo describir la realidad ambiental y social del conflicto en el delta del Níger resultado de las actividades extractivas, especialmente las llevadas a cabo por la empresa Shell, así como exponer las acciones legales más trascendentales realizadas tanto a nivel internacional como nacional y las limitaciones de cada una de ellas. Asimismo, se examinará el caso presentado por cuatro residentes del delta del Níger - junto con la ONG Milieudefensie y Amigos de la Tierra Nigeria - contra Royal Dutch Shell y Shell Petroleum Development Company ante los tribunales holandeses y se analizará la sentencia F. Akpan \& anor-v-Royal Dutch Shell plc \& anor, la cual marca un precedente en la tendencia internacional de responsabilizar a las empresas multinacionales en los Estados de origen por daños en el extranjero.

RESUM: La present nota té com objectiu descriure la realitat ambiental i social del conflicte en el delta del Níger resultat de les activitats extractives, especialment les

\footnotetext{
* Parte del contenido de este trabajo se encuadra en el marco de la investigación "The Dutch Civil Jurisdiction to Bring Claims for Environmental Damages Committed Abroad by Multinational Corporations. The Dutch Shell Nigeria Case", llevada a cabo durante la estancia en el Center for Transboundary Legal Development (CTLD) bajo la supervisión del Dr. Jonathan Verschuuren, profesor de Derecho Internacional del Medio Ambiente y de la Unión Europea de la Universidad de Tilburgo (Holanda).
} 
dutes a terme per l'empresa Shell. Exposar les accions legals més transcendentals portades tant a nivell internacional com a nacional i les limitacions de cadascuna d'elles. Així mateix, examinar el cas dels residents del delta Níger (en conjunt amb l'ONG Milieudefensie i d'Amics de la Terra Nigèria) en contra de Royal Dutch Shell i Shell Petroleum Development Company davant els tribunals holandesos i analitzar la sentencia F. Akpan \& anor -v-Royal Dutch Shell plc \& anor, la qual marca un precedent en la tendència internacional de responsabilitzar a les empreses multinacionals als països d'origen per danys a l'estranger.

ABSTRACT: This note aims to describe the environmental and social reality of the conflict in the Niger Delta as a result of the extractive activities, especially those carried out by the company Shell. It exposes the most significant legal actions taken at the international and national level and the limitations of each of them. Likewise, it reviews the case of four Niger delta residents (in conjunction with Milieudefensie and the NGO Friends of the Earth Nigeria) against Royal Dutch Shell and Shell Petroleum Development Company before the Dutch courts and analyses the ruling F. Akpan \& anor-v-Royal Dutch Shell plc \& anor, whose marks a precedent in the international trend to hold liable multinational companies in the home state for damages abroad.

PALABRAS CLAVE: responsabilidad ambiental, daños ambientales, violaciones de derechos humanos, empresa multinacional, jurisdicción extraterritorial.

PARAULES CLAU: Responsabilitat ambiental — danys ambientals — violacions de drets humans - empresa multinacional — jurisdicció extraterritorial.

KEY WORDS: Environmental liability — environmental damages — human rights violations - multinational corporation - extraterritorial jurisdiction.

Sumario: I. Introducción. II. Conflicto ambiental en el delta del Níger. 1. La actividad de Shell en Nigeria. 2. Causas y consecuencias de los daños ambientales. III. La responsabilidad ambiental de Shell en Nigeria. 1. Limitaciones para la exigencia de la responsabilidad ambiental en Nigeria. 2. Limitaciones de la vía internacional para la reclamación de la responsabilidad internacional. IV. La jurisdicción extraterritorial como vía para exigir la responsabilidad ambiental de Shell. La decisión de los tribunales holandeses. 1. La legislación holandesa para reclamar el daño ambiental. 2. La demanda contra Shell en Holanda. 2.1. Competencia judicial. 2.2. Ley aplicable. 2.3. Aspectos relevantes en la sentencia definitiva del caso Ducth Shell Nigeria. A. Legitimación de la ONG Milieudefensie. B. Responsabilidad de la empresa matriz. C. Vulneración de los derechos humanos. V. Conclusiones. VI. Bibliografía. 


\section{INTRODUCCIÓN}

Nigeria es el escenario de numerosos conflictos de diversa índole: sociales, económicos, políticos, ideológicos y ambientales, entre otros ${ }^{1}$. Una de las regiones del país en la que están presentes estos conflictos es la del delta del Níger. Cabe destacar los conflictos relacionados con las empresas multinacionales del sector de hidrocarburos por la violación de derechos humanos y la degradación ambiental a causa del desarrollo de sus actividades extractivas $^{2}$. La región del delta del Níger tiene una superficie aproximada de 75.000 kilómetros cuadrados ${ }^{3}$ y cuenta con depósitos de petróleo que han generado ingresos de aproximadamente 600.000 millones de dólares estadounidenses desde la década de 1960 para las empresas multinacionales ${ }^{4}$, lo que ha convertido a Nigeria en el primer productor de petróleo de África ${ }^{5}$ y el sexto a nivel mundial ${ }^{6}$.

La economía rentista del petróleo ha atraído a un considerable número de empresas de hidrocarburos a operar en Nigeria ${ }^{7}$. Sus actividades extractivas impactan negativamente en el medio ambiente, del cual depende más del setenta por ciento de la población para

\footnotetext{
${ }^{1}$ Según datos del Instituto de Investigación de Conflictos Internacionales de Heidelberg (HIIK), algunos de los conflictos latentes en el país en 2013 están relacionados con la ideología (Christian groups vs. Muslim groups, Boko Haram vs. government), el predominio subnacional (farmers vs. pastoralists), los recursos (Ijaw Youths, MEND vs. government, International Oil Companies in Niger Delta) o la autonomía (MOSOP, Ogoni vs. government), entre otros. Véase HIIK, Conflict Barometer 2013, HIIK, Heidelberg, 2014.

${ }^{2}$ De acuerdo con FRYNAS, durante la década de 1990 varios casos relacionados con empresas petroleras, entre ellas Shell, Total (anteriormente Elf) y Chevron, fueron llevados ante tribunales nigerianos por daños ocasionados a causa de sus actividades extractivas. FRYNAS, G., "Social and environmental litigation against transnational firms in Africa", Journal of Modern African Studies, vol. 42, núm. 3, 2004. ${ }^{3}$ El delta del Níger es sumamente rico en recursos como tierras, agua, bosques y fauna. Véase PNUD, "Niger Delta Human Development Report", PNUD, Nigeria, 2006.

${ }^{4}$ WURTHMANN, G., "Ways of Using the African Oil Boom for Sustainable Development", Economic Research Working Paper Series, núm. 84, 2006.

${ }^{5}$ Véase US ENERGY INFORMATION ADMINISTRATION (EIA) (2013, 30 de diciembre). Nigeria. Consultado el 22 de enero de 2014, de: http://www.eia.gov/countries/analysisbriefs/Nigeria/nigeria.pdf.

${ }^{6}$ EWEJE, G., "Environmental Costs and Responsabilities Resulting from Oil Exploitation in Developing Countries: The Case of The Niger Delt of Nigeria”, Journal of Business Ethic, vol. 69, núm. 1, 2006.

${ }^{7}$ FRANCIS, P., LAPIN, D. y ROSSIASCO, P., Securing Development and Peace in the Niger Delta. A Social and Conflict Analysis for Change, Woodrow Wilson International Center for Scholars Africa Program, Washington DC, 2011.
} 
su sustento ${ }^{8}$. La empresa que lidera estas actividades y que es la causante de varios incidentes de contaminación en la zona es la Royal Dutch Shell ${ }^{9}$. Esta opera en el delta del Níger con la participación de diversas empresas estatales de Nigeria (joint venture $S P D C)$. En esta joint venture, la empresa Shell cuenta con un 30\% de acciones, la Corporación Nacional Nigeriana del Petróleo un 55\%, Elf Petroleum Nigeria Ltd. el $10 \%$ y Agip el 5\% ${ }^{10}$.

Diversas reclamaciones - legales y no legales - se han interpuesto en el caso Dutch Shell Nigeria ${ }^{11}$. PIGRAU y CARDESA-SALZMANN se refieren a estas como acciones entrelazadas, es decir, acciones de "carácter judicial y no judicial, ante instituciones nacionales, en distintos países, e internacionales, y relativas a diversos aspectos concretos de un mismo problema de fondo, que se manifiesta claramente en el caso del impacto de Shell en Nigeria, pero que puede constatarse también en otros casos"12. Estas acciones tienen como finalidad la responsabilidad de la empresa y la indemnización de las víctimas por las violaciones de derechos humanos y la degradación del medio ambiente. Entre ellas, cabe destacar las acciones presentadas por la ONG Milieudefensie, Amigos de la Tierra Nigeria y cuatro agricultores nigerianos ante los tribunales holandeses contra las empresas Royal Dutch Shell PLC y Shell Development Company Petroleum de Nigeria (SDCP). De los cuatro casos anteriores, destaca la sentencia del caso Akpan vs. Shell, la cual podría consolidarse como un precedente para los litigios transnacionales para responsabilizar a la empresa multinacional por violaciones de derechos humanos y daños al medio ambiente en el

\footnotetext{
${ }^{8}$ EBEGBUlem, J. C., EKPE, D. y ADEJUMO, T. O., "Oil Exploration and Poverty in the Niger Delta Region of Nigeria: A Critical Analysis", International Journal of Business and Social Science, vol. 4, núm. 3, 2013.

${ }^{9}$ Shell es una empresa de hidrocarburos anglo-holandesa que tiene intereses en el sector petrolífero, del gas natural y del refinado de gasolinas. En el Reino Unido ha sido registrada y tiene su sede principal en Holanda. La Royal Dutch Shell comenzó la explotación petrolera en el delta del Níger en el año 1958 y ha mantenido una posición dominante desde su llegada al país africano en 1937. Véase página web de Shell (http://www.shell.es/aboutshell.html).

${ }^{10}$ Véase página web de Shell: www.shell.com.

${ }^{11}$ De manera similar, pero en un sentido más amplio, nos referimos al caso Dutch Shell Nigeria como lo señala ENNEKING en su artículo "The Future of Foreign Direct Liability? Exploring the International Relevance of the Dutch Shell Nigeria Case". Por su parte, la autora se refiere en concreto a las acciones de responsabilidad extranjera directa (Foreign Direct Liability) contra la empresa; y, por nuestra parte, además de hacer referencia a estas acciones, también aludimos a aquellas acciones interpuestas ante los tribunales del Estado anfitrión y los tribunales supranacionales.

${ }^{12}$ Véase PIGRAU, A. y CARDESA-SALZMANN, A., “Acciones entrelazadas contra daños ambientales graves: el impacto e Shell en Nigeria”, Revista de la Facultad de Derecho PUCP, núm. 70, 2013.
} 
extranjero $^{13}$. VAN DER HEIJDEN destaca que es el primer caso civil holandés ante tribunales del Estado de origen de una empresa multinacional por supuestos abusos contra derechos humanos y degradación ambiental en Nigeria ${ }^{14}$.

\section{CONFLICTO AMBIENTAL EN EL DELTA DEL NÍGER}

\section{La actividad de Shell en Nigeria}

Actualmente, la industria de los hidrocarburos en Nigeria representa el $97 \%$ de los ingresos de divisas y constituye el 79,5\% de los ingresos del Estado ${ }^{15}$. En 1956, la empresa Royal Dutch Shell (en adelante, Shell) detectó yacimientos de petróleo en Oloibiri, estado de Bayelsa, y dos años más tarde comenzó la actividad extractiva en la zona; desde entonces es el mayor operador del país y una de las principales empresas petroleras en la región ${ }^{16}$. La principal producción de petróleo y gas de la empresa, que supone alrededor del $40 \%$ de la producción del país ${ }^{17}$, se realiza en tierras y pantanos del delta del Níger. La filial, Shell Petroleum Development Company (SPDC o Shell Nigeria), alcanza una producción de más de un millón de barriles diarios y gestiona unos 6.000 kilómetros de oleoductos y tuberías, 87 estaciones de petróleo, 8 plantas de gas natural y más de 1.000 pozos de extracción ${ }^{18}$. Las actividades de Shell en Nigeria han llamado la atención de la comunidad internacional principalmente por tres razones: 1) es el mayor productor de petróleo en la historia de Nigeria y disfrutó de un monopolio y una relación privilegiada con el gobierno durante sus inicios; 2) las

\footnotetext{
13 JÄGERS, N., JESSE, K. y VERSCHUUREN, J., "The Future of Corporate Liability for Extraterritorial Human Rights Abuses: The Dutch Case against Shell”, American Journal of International Law, vol. 4, núm. 197, 2013.

14 VAN DER HEIJDEN, M. J., Transnational Corporations and Human Rights Liabilities. Linking Standards of International Public Law to National Civil Litigation Procedures, Intersentia, Amberes, 2012.

${ }^{15}$ COMMITTEE ON THE NIGER DELTA (2008, 8 de septiembre), "Report of the Technical Committee on the Niger Delta", volumen 1, p. 102.

16 Consúltense las estadísticas de la Nigerian National Petroleum Corporation (NNPC) en: http://www.nnpcgroup.com/PublicRelations/OilandGasStatistics.aspx.

17 CRUZ CARDOZO, A. P., Análisis de la presencia de petroleras occidentales y la agudización de conflictos político-económicos en el delta del Níger. Caso: la Royal Dutch Shell y el Movimiento para la Emancipación del Delta del Niger (MEND) 2006-2010, Universidad Colegio Mayor de Nuestra Señora del Rosario, Bogotá, 2011.

18 GARCÍA ÁLVAREZ, L., "Daños privados por contaminación en el tráfico externo: A propósito del caso Akpan vs. Shell (Nigeria)”, Cuadernos de Derecho Transnacional, vol. 5, núm. 2, 2013.
} 
instalaciones de la empresa se encuentran dentro o en las inmediaciones de zonas habitadas, lo que las expone a protestas por parte de la población; y 3) la empresa ha sido acusada de complicidad en el presunto genocidio del pueblo ogoni ${ }^{19}$.

La actividad de Shell Nigeria ha generado protestas por parte de la población; entre las más destacadas se encuentran las llevadas a cabo por el Movimiento para la Supervivencia del Pueblo Ogoni (MOSOP, por sus siglas en inglés) con la finalidad de hacer campaña contra los daños ambientales causados por la extracción de petróleo en la región Ogoni de Nigeria, conseguir una mayor autonomía para este grupo étnico y acusar a la empresa del ya mencionado genocidio del pueblo ogoni ${ }^{20}$. Ante las protestas, la empresa y el gobierno ${ }^{21}$ han respondido de forma violenta contra el pueblo ogoni. En 1994, como represión, miembros del MOSOP fueron detenidos de manera ilegal y juzgados por asesinato mediante procedimientos que violaban los estándares internacionales de un juicio justo; un año más tarde fueron condenados y luego ejecutados en la horca ${ }^{22}$. A esta situación de protestas se suma el impacto negativo de la actividad extractiva de la empresa sobre el medio ambiente y sus inherentes consecuencias en la población.

\section{Causas y consecuencias de los daños ambientales}

PRIGAU y CARDESA-SALZMANN señalan que la historia de la explotación del petróleo en Nigeria ha estado plagada de incidentes de contaminación ${ }^{23}$. Esta explotación perjudicial para el medio ambiente afecta principalmente a la región del delta del Níger y conlleva no solo impactos negativos para el medio ambiente, sino también para el desarrollo socioeconómico de la región ${ }^{24}$. Las actividades extractivas en

\footnotetext{
${ }^{19}$ HRW (1999, enero), "The Price of Oil: Corporate Responsibility and Human Rights Violations in Nigeria's Oil Producing Communities". Consultado el 2 de abril de 2014, de: http://www.hrw.org/reports/1999/nigeria/nigeria0199.pdf.

${ }^{20}$ HRW, “The Price...” cit., p. 113.

${ }^{21}$ PIGRAU y CARDESA-SALZMANN hacen referencia a la estrecha relación entre la empresa y los distintos gobiernos de Nigeria - muchos de ellos gobiernos militares surgidos de golpes de Estado- y a la colaboración para reprimir la oposición popular a las actividades extractivas en la región facilitando infraestructuras y apoyo logístico. PIGRAU, A. y CARDESA-SALZMANN, A., "Acciones..." cit., p. 219.

22 Ídem.

${ }^{23}$ Ibídem, p. 220.

${ }^{24}$ EBEGBULEM, J. C., EKPE, D. y ADEJUMO, T. O., “Oil...” cit., pp. 280-281.
} 
la región son llevadas a cabo bajo un "Double standard", es decir, por debajo de los estándares aceptados internacionalmente en el sector ${ }^{25}$. Por ejemplo, sin aplicar la mejor tecnología disponible ni las prácticas de prevención y control de vertidos. De acuerdo con el reporte "Nigeria: Petróleo, contaminación y pobreza en el Delta del Níger" de Amnistía Internacional $^{26}$, los principales daños ambientales ocasionados en el delta del Níger se deben a la quema de gases, los vertidos procedentes de los oleoductos y los vertidos procedentes de la extracción de petróleo. En relación con los vertidos, EBEGBULEM (et. ál.) señala que son la principal variable que afecta a las comunidades en la región del delta de Níger $^{27}$. Según Amnistía Internacional ${ }^{28}$, los constantes vertidos son consecuencia de una deficiente infraestructura, ya sea debido a la corrosión o a un mantenimiento escaso de las tuberías que produce las filtraciones o fugas durante el proceso de refinamiento del petróleo. Asimismo, un gran número de vertidos se deben al sabotaje. Por su parte, OKOKO enfatiza que el método de "oil-pipe flare" empleado por las empresas en la región para la quema de gases es nocivo para el medio ambiente debido a que la llama produce altos niveles de contaminación atmosférica y a que el método no cuenta con previsiones para la reducción de la contaminación $^{29}$.

En cualquiera de las situaciones (quema de gases o vertidos) se ejerce una presión sobre el medio ambiente que convierte a la región en una de las más contaminadas del mundo ${ }^{30}$; a su vez, la región permanece como una de las más pobres ${ }^{31}$, con un bajo nivel

\footnotetext{
25 STEINER, R., Double Standar. Shell practices in Nigeria Compared With International Standard to Prevent and Control Pipeline oil Spills and the Deepwater Horizon Oil Spill, Friends of the Earth Netherlands, Ámsterdam, 2010.
}

${ }^{26}$ AMNISTÍA INTERNACIONAL, "Nigeria: Petróleo, contaminación y pobreza en el Delta del Níger", Amnistía internacional, Londres, 2009.

${ }^{27}$ EBEGBULEM, J. C., EKPE, D. y ADEJUMO, T. O., “Oil...” cit., p. 282.

${ }^{28}$ AMNISTÍA INTERNACIONAL, "Nigeria...” cit., pp. 16-21.

${ }^{29}$ OKOKO, K., "Shell Petroleum Development Company (S.P.D.C.) - Host Community Relation Study", en Ebegbulem, J. C., Ekpe, D. y Adejumo, T. O., "Oil Exploration and Poverty in the Niger Delta Region of Nigeria: A Critical Analysis", International Journal of Business and Social Science, vol. 4, núm. 3, 2013, p. 282.

${ }^{30}$ UNEP, Environmental Assessment of Ogoniland, UNEP, Nairobi, 2011.

${ }^{31}$ Nigeria se posiciona en el lugar 153, de un total de 186 países, de la lista de Índice de Desarrollo Humano elaborada por el PNUD en 2012. Véase "Human Development Index and its components", de https://data.undp.org/dataset/Table-1-Human-Development-Index-and-its-components/wxub-qc5k. EBEGBULEM (et. ál.) describe algunas de las carencias de la población y señala que "seventy percent of the inhabitants still live in rural subsistent existence characterized by a total absence of such basic facilities as electricity, pipe-bome water, hospitals, proper housing and motorable roads". EBEGBULEM, J. C., EKPE, D. y ADEJUMO, T. O., “Oil...” cit., p. 284. 
de desarrollo social y económico y ambientalmente degradada ${ }^{32}$ a consecuencia de la afectación a la agricultura y la pesca, que son las principales fuentes de sustento de la población $^{33}$. Por una parte, los vertidos afectan a la calidad y fertilidad del suelo, llegando a destruir los cultivos $^{34}$, y, por otra, contaminan las aguas, afectando a su potabilidad y a sus posibles usos domésticos y perjudicando a la biodiversidad, especialmente los bancos de peces ${ }^{35}$. En consecuencia, de acuerdo con EBEGBULEM (et. ál.), la población de la región del delta del Níger vive bajo condiciones sanitarias inadecuadas, así como en un medio ambiente contaminado que limita la calidad de vida $^{36}$. Según un grupo de expertos, en los cincuenta años de actividad extractiva en la región se han vertido aproximadamente entre 9 y 13 millones de barriles ${ }^{37}$. Los daños ambientales ocasionados en la región están valorados en 10.000 millones de dólares y se requeriría de 25 a 30 años para su recuperación ${ }^{38}$.

\section{LA RESPONSABILIDAD AMBIENTAL DE SHELL EN NIGERIA}

\section{Limitaciones para la exigencia de la responsabilidad ambiental en Nigeria}

PIGRAU (et. ál.) señala que en primera instancia la vía legal para buscar una reparación por daños al medio ambiente y violaciones de derechos humanos provocados por las empresas es ante los tribunales nacionales del Estado donde se causó el daño (forum delicti commissi) ${ }^{39}$. Por lo tanto, el Estado anfitrión (host State) debe observar un comportamiento diligente encaminado a que determinadas actividades realizadas por

\footnotetext{
32 TUNDE, O. I. y TANSHI, I., "Ecological Restoration Of Oil Spill Sites in The Niger Delta, Nigeria", Journal of Sustainable Development in Africa, vol. 11, núm. 2, 2009.

${ }^{33}$ EBEGBULEM, J. C., EKPE, D. y ADEJUMO, T. O., “Oil...” cit., p. 280.

34 Ídem.

${ }^{35}$ AMNISTÍA INTERNACIONAL, "Nigeria...” cit., p. 90.

${ }^{36}$ EBEGBULEM, J. C., EKPE, D. y ADEJUMO, T. O., “Oil...” cit., p. 284.

${ }^{37}$ UICN et. ál. (2006, 31 de mayo), "Niger Delta Natural Resources Damage Assessment and Restoration Project, Phase I Scoping Report”, p. 1. Consultado el 14 de enero de 2014, de: http://predoc.org/docs/index-188779.html.

${ }^{38}$ UNEP, Environmental... cit., pp. 226-227.

39 PIGRAU, A., BORRÀS, S., JARIA, J. y CARDESA-SALZMANN, A., "The Interplay of National, Transnational and International Litigation for Environmental Justice: Seeking Effective Means of Redress for Grave Environmental Damage", ISEE Conference 2012 - Ecological Economics and Rio+20: Challenges and Contributions for a Green Economy, Río de Janeiro (Brasil).
} 
particulares (personas físicas o legales) en su territorio o bajo su jurisdicción no ocasionen daños a sus nacionales o a otros Estados ${ }^{40}$. En este sentido, la legislación nigeriana prevé la responsabilidad de las empresas por los vertidos causados y la obligación de indemnizar a los perjudicados. La compensación está contemplada en el apartado 11.5.c de la Oil pipeline Act de 1990, que dispone que "to any person suffering damage (other than on account of his own default or on account of the malicious act of a third person) as a consequence of any breakage of or leakage from the pipeline or an ancillary installation, for any such damage not otherwise made good"41. Asimismo, se establece la obligación por parte de las empresas de realizar inmediatamente operaciones de limpieza; de acuerdo con el apartado 22.2 de la Nigerian Federal Environmental Protection Agency Act de 1992, la empresa debe "begin immediate clean-up operations following the best available clean-up practice and removal methods" $"$. Finalmente, cabe señalar que la Nigerian Petroleum Act/69, en su apartado 8.1.g, contempla que el Minister of Petroleum Resources puede suspender operaciones "where in his opinion a contravention of this Act or any regulations made thereunder has been o may been or is likely to be committed"43.

En el caso de estudio se han interpuesto varias acciones por daños al medio ambiente en contra de la empresa Shell Nigeria ante los tribunales nigerianos por vertidos de petróleo. Sin embargo, los procesos suelen prolongarse en el tiempo y las pocas sentencias dictadas no contribuyen a la restauración del medio ambiente ${ }^{44}$. FRYNAS destaca las acciones contra la empresa Shell ante los tribunales nigerianos y señala que "During the period 1981-86, twenty-four compensation claims against Shell went to court in Nigeria (Adewale 1989: 93). In early 1998, Shell was reportedly involved in over 500 pending court cases in Nigeria, of which $70 \%$ or roughly 350 cases dealt with oil spills, the other $30 \%$ or 150 cases mostly with other types of damage from oil operations, contracts, employment and taxation" 45 . Uno de los casos iniciados contra la

\footnotetext{
${ }^{40}$ LOZANO CONTRERAS, J. F., La noción de debida diligencia en Derecho internacional público, Atelier, Barcelona, 2007.

41 Véase Petroleum Act, cap. $350, \quad 1990, \quad$ de: http://www.babalakinandco.com/resources/lawsnigeria/LAWS/90350petroleum\%20act.htm.

42 Véase artículo 22.2.b Nigerian Federal Environmental Protection Agency Act, de: http://www.placng.org/new/laws/F10.pdf.

43 Véase artículo 8.1.g. Nigerian Petroleum Act/69, de: http://www.lexadin.nl/wlg/legis/nofr/oeur/arch/nig/petroleumact.pdf.

${ }^{44}$ FRYNAS, G., "Social...” cit., pp. 380-381.

${ }^{45}$ Ibídem, p. 371.
} 
empresa Shell en Nigeria es el del 20 de junio de 2005. Representantes de la comunidad de Iwherekan presentaron reclamaciones por la contaminación atmosférica consecuencia de la quema de gases que afecta a la salud humana y al medio ambiente ${ }^{46}$. En noviembre de 2005, el Alto Tribunal Federal de Nigeria dictó sentencia que determinaba que la empresa debía cesar la quema de gas en el delta del Níger debido a que era una práctica contraria a la constitución ${ }^{47}$. Shell Nigeria apeló la decisión. En diciembre del mismo año se presentó un nuevo recurso por parte de las víctimas por no cesar la quema del gas ${ }^{48}$. El Tribunal Supremo de Nigeria decidió en abril de 2006 que, en el período de un año, Shell Nigeria debía cesar la quema de gas en la comunidad de Iwherekan $^{49}$. Como consecuencia de lo anterior se adoptaron la Gas Flaring Prohibition and Punishment Bill de 2009 y la Petroleum Industry Bill de $2012^{50}$.

En otro caso, el 5 de julio de 2010 el Tribunal Federal de Nigeria resolvió en contra de Shell Nigeria, y le ordenó pagar 105 millones de dólares a la comunidad de EjamaEbubu por daños y pérdidas causados por los vertidos de petróleo ocurridos desde 1970, los cuales habían afectado a más de 255 hectáreas $\left(2,5 \mathrm{~km}^{2}\right)^{51}$. Esta compensación fue calculada sobre la base de los daños ocasionados al suelo, la pérdida de ingresos derivados de la agricultura y la caza, la contaminación de las reservas de agua, los riesgos a la salud y los impactos psicológicos, entre otros aspectos. Igualmente, el juez dictó la obligación de proceder a descontaminar y restaurar la zona a las condiciones anteriores al vertido.

A pesar de los intentos por parte de las víctimas de obtener una compensación por los daños sufridos, el poder económico y político de Shell puede representar un obstáculo para responsabilizar a la empresa y obligarla a remediar los daños ambientales. Desde la

\footnotetext{
${ }^{46}$ WRM, "Nigeria: la quema de gas, contribuye al cambio climático y a la violación de los derechos humanos", Boletín Movimiento por los Bosques Tropicales, núm. 136, noviembre de 2008. Consultado el 20 de febrero de 2014, de: http://www.wrm.org.uy/boletin/136/opinion.html.

47 Véase sentencia del Alto Tribunal Federal de Nigeria, Gbemre v Shell Petroleum Development Company Nigeria Limited and Others (2005) AHRLR 151 (NgHC 2005), de: http://www1.chr.up.ac.za/index.php/browse-by-subject/418-nigeria-gbemre-v-shell-petroleumdevelopment-company-nigeria-limited-and-others-2005-ahrlr-151-nghc-2005.html

${ }^{48}$ PIGRAU, A. y CARDESA-SALZMANN, A., “Acciones...” cit., p. 222.

${ }^{49}$ Véase Shell to Sea (2006, 12 de abril) Shell ordered to stop gas flaring by Nigerian Court. Consultado el 10 de febrero de 2014, de: http://www.shelltosea.com/node/774?page=6.

${ }^{50}$ PIGRAU, A. y CARDESA-SALZMANN, A., “Acciones...” cit., p. 221.

${ }^{51}$ MARTÍNEZ ALIER, J. (2011, 17 de febrero), "El caso Chevron Texaco en Ecuador: una muy buena sentencia que podría ser un poco mejor". Consultado el 18 de enero de 2014, de: http://alainet.org/active/44476.
} 
perspectiva de los derechos humanos, WESCHKA indica que el poder económico de las empresas multinacionales y la deslocalización de sus actividades, así como la dependencia de varios países de la inversión extranjera, en especial en países en desarrollo, comportan una falta de acciones contra las empresas multinacionales que violan los derechos humanos en sus territorios ${ }^{52}$. Por su parte, MORGERA destaca el impacto de los tratados de inversión en la soberanía de los Estados (particularmente en los países en desarrollo) y en su capacidad para aplicar y mejorar su legislación ambiental $^{53}$. Considerando el gran interés que pueden representar los tratados de inversión, los Estados restringen su soberanía, lo que afecta a su capacidad para legislar y tomar medidas contra los abusos de las empresas ${ }^{54}$. Las posibles acciones por parte de los Estados contra las empresas pueden poner en riesgo la inversión, ya que las empresas pueden trasladar sus actividades a entornos más favorables para sus actividades $^{55}$ (bajos estándares ambientales y laborales, capacidades limitadas de la aplicación de la normativa y entornos de corrupción para el desarrollo de sus actividades económicas) ${ }^{56}$. Por lo tanto, la asimetría de poder y la necesidad de la inversión extranjera de algunos Estados pueden limitar el reconocimiento y la compensación de las víctimas de daños ambientales causados por las empresas multinacionales.

\section{Limitaciones de la vía internacional para la reclamación de la responsabilidad internacional}

En vista de los obstáculos y las limitaciones en los ordenamientos jurídicos de los Estados anfitriones para responsabilizar a las empresas y obtener una indemnización para las víctimas de los daños ambientales, los afectados optan por interponer acciones

\footnotetext{
${ }^{52}$ WESCHKA, M., "Human Rights and Multinational Enterprises: How Can Multinational Enterprises Be Held Responsible for Human Rights Violations Committed Abroad?", Zeitschrift für ausländisches öffentliches Recht und Völkerrecht, núm. 66, 2006.

53 MORGERA, E., Corporate accountability in international environmental law, Oxford University Press, Nueva York, 2009.

${ }^{54}$ Ibídem, pp. 26-25.

${ }^{55}$ WESCHKA, M., "Human..." cit., p. 628.

${ }^{56}$ En este sentido, WESCHKA señala lo siguiente: "This significant economic power combined with their ability to choose globally the State with the most advantageous conditions for setting up business, which will very often include the lowest labor costs and the laxest rules for the protection of the environment, conveys substantial bargaining power to MNEs, especially with regard to developing countries”. Ídem.
} 
ante diversas instituciones supranacionales del ámbito de los derechos humanos. Desde una perspectiva internacional, AUGENSTEIN resalta esta tendencia de recurrir ante tribunales de derechos humanos debido a que "there is distinct reluctance in international environmental law to recognise the duties of States towards individuals, or to grant individuals the right to pursue remedies for violations of State-to-State obligations - which is why victims of environmental degradation have increasingly turned to human rights tribunals for remediation" ${ }^{, 57}$. Entre las acciones interpuestas a raíz de la actividad de Shell en Nigeria, se encuentran las llevadas ante el sistema africano de protección de los derechos humanos. La Comisión Africana de Derechos Humanos y de los Pueblos, en su decisión de 2001, consideró la violación de los artículos 2, 4, 14, 16, 18(1), 21 y 24 de la Carta Africana de Derechos Humanos y de los Pueblos $^{58}$ (conocida como Carta de Banjul) por parte del Estado nigeriano. En la decisión, la Comisión señaló las violaciones sufridas por el pueblo ogoni al derecho a la vida, a la alimentación, a un medio ambiente sano y a la soberanía sobre los recursos naturales. En dichas violaciones estuvieron implicadas la empresa Nigerian National Petroleum Company y la filial (subsidiary) de la empresa Shell en Nigeria, Shell Petroleum Development Corporation. Desde un punto de vista jurídico, cabe destacar que la Comisión resaltó el deber del Estado de proteger el medio ambiente para garantizar lo dispuesto en el artículo 24 de la Carta de Banjul ${ }^{59}$, señalando lo siguiente: "It requires the State to take reasonable and other measures to prevent pollution and ecological degradation, to promote conservation, and to secure an ecologically sustainable development and use of natural resources" ${ }^{\prime 60}$. Asimismo, la Comisión señaló las obligaciones del Estado nigeriano en relación con las empresas que operan en el país con el fin de prevenir la vulneración de los derechos de las personas: "Governments have a duty to protect their citizens, not only through appropriate legislation and

\footnotetext{
57 AUGENSTEIN, D. (2011, 26 de septiembre), "The Human Rights Dimension of Environmental Protection in EU External Relations Post-Lisbon". Consultado el 5 de abril de 2014, de: http://ssrn.com/abstract=1933675.

${ }^{58}$ Véase Carta Africana de Derechos Humanos y de los Pueblos. Aprobada el 27 de julio de 1981 durante la XVIII Asamblea de Jefes de Estado y Gobierno de la Organización de la Unidad Africana, reunida en Nairobi, Kenia. Consultado de: http://www.acnur.org/biblioteca/pdf/1297.pdf?view=1.

${ }^{59}$ Véase artículo 24 de la Carta Africana de Derechos Humanos y de los Pueblos: "All peoples shall have the right to a general satisfactory environment favorable to their development".

${ }^{60}$ Véase sentencia de la Comisión Africana de Derechos Humanos y de los Pueblos, The Social and Economic Rights Action Center and the Center for Economic and Social Rights v. Nigeria, Comm. No. 155/96 (2001). Párrafo 52, de: http://www1.umn.edu/humanrts/africa/comcases/155-96.html.
} 
effective enforcement but also by protecting them from damaging acts that may be perpetrated by private parties"61. En este sentido, se determinó que el Gobierno nigeriano ha dado luz verde a agentes privados, particularmente a las empresas de hidrocarburos, para afectar al bienestar del pueblo ogoni ${ }^{62}$, con lo que se viola lo estipulado en el artículo 21 de la Carta Africana de Derechos Humanos y de los Pueblos. Por lo tanto, el Gobierno nigeriano ha faltado a su deber de proteger al pueblo ogoni de actos dañinos perpetrados por las empresas petroleras al no controlar y regular las actividades de estas y al permitirles la violación de los derechos con impunidad ${ }^{63}$. Asimismo, en 2009 se interpuso una demanda ante el Tribunal de Justicia de la Comunidad Económica de Estados de África Occidental (ECOWAS, por sus siglas en inglés) contra el presidente de la República de Nigeria, el fiscal general, la empresa pública Nigerian National Petroleum Corporation (NNPC) — accionista mayoritario en todas las joint ventures - , Shell Petroleum Development Company — filial de Royal Dutch Shell-, Elf Petroleum Nigeria Ltd., Agip Nigeria Plc., Chevron Nigeria Oil Plc. y ExxonMobil Corporation en la que se alega, por una parte, la violación de diversos derechos (a la alimentación, al trabajo, a la salud, al agua, a la vida, a la dignidad humana, a un medio ambiente sano y al desarrollo económico y social, entre otros) por la contaminación derivada de las actividades extractivas en el delta del Níger, y, por otra, la incapacidad del Gobierno nigeriano para hacer cumplir la legislación ambiental. En su decisión del 10 de diciembre de 2010, el tribunal reconoció el derecho de los pueblos a su desarrollo económico, social y cultural, el derecho de los pueblos a un medio ambiente sano y favorable para su desarrollo, y, finalmente, la obligación de los Estados de tomar medidas para proteger estos derechos de sus pueblos frente a agentes no estatales que pudieran vulnerarlos. Cabe resaltar que el tribunal señaló la laguna legal del derecho internacional para responsabilizar a una empresa desde este ámbito, apuntando que "one of the paradoxes that characterize International Law presently is the fact that States and individuals can be held accountable internationally, while companies cannot" ${ }^{\prime 64}$. Es decir, el incumplimiento de las normas internacionales por parte de las

\footnotetext{
${ }^{61}$ Véase párrafo 57 ibídem.

${ }^{62}$ Véase párrafo 58 ibídem.

63 OREllanA, M., Derechos Humanos y Ambiente: Desafios para el Sistema Interamericano de Derechos Humanos, Center for International Environmental Law - CIEL, Washington, 2007.

${ }^{64}$ Véase sentencia del Tribunal de Justicia de la Comunidad Económica de Estados de África Occidental, SERAP v. Nigeria, Ruling, Suit No: ECW/CCJ/APP/08/09 and RUL. No: ECW/CCJ/APP/07/10. Párrafo 65, de: http://www.worldcourts.com/ecowasccj/eng/decisions/2010.12.10_SERAP_v_Nigeria.htm.
} 
empresas no conlleva su responsabilidad debido a que carece de personalidad jurídica a nivel internacional.

Históricamente, los derechos y las obligaciones internacionales son vinculantes solo para los Estados, considerados como los sujetos por excelencia del derecho internacional, y las organizaciones internacionales ${ }^{65}$, por lo que el alcance de esta rama del derecho se limita a la falta de plena personalidad jurídica internacional de las empresas multinacionales, a pesar del hecho de que actualmente desempeñan un papel importante en el plano internacional. En este sentido, JOHNS señala: "Despite their profound influence upon international affairs, transnationals corporations are more notable in their absence from international discourse, than in their presence" ${ }^{\text {"66. En }}$ consecuencia, los tribunales internacionales no tienen jurisdicción sobre las empresas multinacionales ${ }^{67}$, exceptuando casos de arbitraje entre un Estado y una empresa multinacional con el fin de resolver una controversia relacionada con la protección de la inversión y con las transacciones comerciales ${ }^{68}$. La falta de personalidad jurídica internacional de las empresas puede ser tomada como una ventaja legal y económica por parte de estas ya que no responden directamente por el incumplimiento de las normas internacionales. Además de esto, no se puede obviar lo señalado por ZERK: "International law does not provide easy solutions to the social and environmental issues posed by multinationals ${ }^{69}$,"

En las últimas décadas ha habido varios intentos de establecer obligaciones internacionales para las empresas, entre ellos: las Líneas Directrices de la OCDE para Empresas Multinacionales, adoptadas en junio de 1976; la Declaración Tripartita de

${ }^{65}$ BECERRA RAMÍREZ, M., Panorama del Derecho Mexicano. Derecho Internacional Público, McGraw-Hill, México, DF, 1997.

${ }^{66}$ JOHNS, F., "The invisibility of the Transnational Corporations: An Analysis of International Law and Legal Theory", Melbourne University Law Review, vol. 19, 1993-1994.

${ }^{67}$ BORRÁS PENTINAT, S. y VILASECA BOIXAREU, I., "Los conflictos ambientales causados por empresas transnacionales: realidades y retos jurídicos internacionales", en Soares Stersi dos Santos, R. y Annoni, D. (coord.), Cooperaçao e conflictos Internacionais: Globalizaçao, Regionalismo e Atores, Curitiba, Multideia, 2014.

${ }^{68}$ Por ejemplo, el caso de Chevron / Texaco en Ecuador, donde la empresa promovió un procedimiento arbitral contra la República del Ecuador debido a ciertas acciones por parte del Estado que violaban los términos del acuerdo bilateral de inversión entre los Estados Unidos y Ecuador. Véase Chevron Corporation and Texaco Petroleum Company v. The Republic of Ecuador, PCA Case No 2009-23, Order for Interim Measures (2 de abril de 2014), de: http://www.italaw.com/sites/default/files/casedocuments/ita0155_0.pdf.

69 ZERK, J.A., Multinationals and Corporate Social Responsibility. Limitations and Opportunities in International Law, Cambridge University Press, Cambridge, 2006. 
Principios sobre las Empresas Multinacionales y la Política Social, elaborada en el marco de la Organización Internacional del Trabajo en 1977; el Proyecto de las Naciones Unidas de un Código de Conducta para las Empresas Transnacionales de 1982; el Pacto Mundial (Global Compact); y, el más reciente, los Principios Rectores de las Naciones Unidas sobre Empresas y Derechos Humanos. Sin embargo, estos códigos de conducta se han caracterizado por la falta de compromisos vinculantes y su carácter voluntario, característica que ha sido bien acogida por las empresas multinacionales. Asimismo, las empresas optan por adoptar códigos de conducta internos, en el marco de lo que se conoce como responsabilidad social corporativa $(\mathrm{RSC})^{70}$, que comprende un conjunto de normas y principios que recogen valores y acciones responsables con el fin de evitar regulaciones de carácter obligatorio.

Desde el ámbito internacional, como señalan BORRÁS y VILASECA, cabe la posibilidad de responsabilizar internacionalmente a los Estados de los daños ocasionados por las empresas por falta de la debida diligencia (due diligence) en las actividades empresariales dentro de su territorio o bajo su jurisdicción. Asimismo, como señalan las autoras: “[...] los Estados están, en mayor o menor grado, relacionados con las actividades desarrolladas por las ETNs en su territorio, y en cualquier caso están obligados internacionalmente a hacer respetar en su territorio los derechos humanos y los tratados con los que se hayan comprometido"71. A pesar de esto, los Estados no están dispuestos a asumir la responsabilidad internacional por los hechos ilícitos — que ocasionen daños al medio ambiente- cometidos por particulares en su territorio o en otros lugares bajo su jurisdicción, a excepción de casos relacionados con actividades extremadamente peligrosas no prohibidas por el derecho internacional ${ }^{72}$. PIGRAU (et. ál.) explica que a través de la inclusión del principio de "quien contamina paga" (PPP, por sus siglas inglés) los costos de las medidas de prevención y reducción de la contaminación se asignan, en el derecho internacional, a los operadores de las actividades industriales. Esta cuestión se ve reflejada en un considerable número de tratados internacionales en los que se establecen mecanismos de responsabilidad civil

70 PEÑA GUTIÉRREZ, D., "Responsabilidad Social Corporativa", en Zubizarrea Hernández, J., González, E. y Ramiro, P., Diccionario crítico de empresas transnacionales. Claves para enfrentar el poder de las grandes corporaciones, Icaria, Barcelona, 2012.

${ }^{71}$ BORRÁS PENTINAT, S. y VILASECA BOIXAREU, I., “Los conflictos...” cit., pp. 163-164.

${ }^{72}$ PIGRAU SOLÉ, A., "La responsabilidad internacional de los Estados por daños al medio ambiente", en Sindico, F., Fernández Egea, M. y Borràs Pentinat, S. (eds), Derecho internacional del medio ambiente: Una visión desde Iberoamérica, Cameron May-CMP Publishing Ltd., Londres, 2011. 
para indemnizar a las víctimas por los daños sufridos. Por ejemplo, inter alia, la Convención de Bruselas de 17 de diciembre de 1971 sobre responsabilidad civil en materia de transporte marítimo del material nuclear, el Protocolo de 2003 del Convenio Internacional sobre la constitución de un fondo internacional de indemnización de daños debidos a contaminación por hidrocarburos o el Protocolo de Basilea sobre responsabilidad e indemnización por daños resultantes de los movimientos transfronterizos de desechos peligrosos y su eliminación de 1999.

A pesar del gran número de casos en los que se acusa a una empresa por daños a bienes e intereses protegidos por el derecho internacional como el medio ambiente, queda pendiente el reconocimiento de la personalidad jurídica internacional y la responsabilidad directa de las empresas por el incumplimiento de la normativa internacional.

\section{LA JURISDICCIÓN EXTRATERRITORIAL COMO VÍA PARA EXIGIR LA RESPONSABILIDAD AMBIENTAL DE SHELL. LA DECISIÓN DE LOS TRIBUNALES HOLANDESES}

La jurisdicción extraterritorial, en términos generales, es la competencia de un Estado a través de ordenamientos legales e instituciones judiciales para llevar a cabo el ejercicio de su autoridad sobre actores y actividades que operan en otro territorio ${ }^{73}$. El caso Dutch Shell Nigeria ha traspasado fronteras y se han interpuesto acciones por los daños ambientales y las violaciones de derechos humanos en jurisdicciones distintas del Estado donde han sucedido los hechos: en el Reino Unido, donde la empresa tiene sus oficinas centrales $^{74}$; en los Estados Unidos a través de la jurisdicción del Alien Tort Claim $\mathrm{Act}^{75}$ (ATCA) $^{76}$; y, finalmente, en Holanda, donde la empresa tiene su sede. Por

\footnotetext{
73 ZERK, J. A. (2010, 1 de junio), "Extraterritorial Jurisdiction: Lessons for the Business and Human Rights sphere from six regulatory areas". Consultado el 4 de febrero de 2012, de: http://www.hks.harvard.edu/m-rcbg/CSRI/publications/workingpaper_59_zerk.pdf.

74 Véase Bodo Community $v$ Shell Petroleum Development Company of Nigeria, de: http://platformlondon.org/wp-content/uploads/2012/06/The-Bodo-Community-and-The-Shell-PetroleumDevelopment-Company-of-Nigeria-Ltd.pdf.

${ }^{75}$ El Alien Tort Claims Act (ATCA) es una ley federal estadounidense, aprobada en 1789, que otorga competencia a los tribunales federales de ese país para conocer de demandas de responsabilidad civil interpuestas por extranjeros ante violaciones del derecho internacional. El ACTA se había constituido como una vía para responsabilizar a las empresas por violaciones de derechos humanos cometidas en un Estado tercero. Sin embargo, la resolución del caso Kiobel, et ál. vs. Royal Dutch Petroleum Co., et ál dictada bajo la jurisdicción del ATCA supone un gran retroceso en la responsabilidad de empresas multinacionales por daños ocurridos en Estados terceros donde a veces hay obstáculos para reconocer y
} 
consiguiente, el caso adquiere una relevancia importante en los litigios transnacionales para responsabilizar a una empresa por los daños ambientales ocasionados por una filial que opera en un país en desarrollo.

\section{La legislación holandesa para reclamar el daño ambiental}

Holanda es un país que alberga un gran número de empresas que operan en diversos países del mundo, entre ellas Philips, Shell, Unilever y Heineken. Algunas de ellas se han visto involucradas en conflictos socioambientales. Es el caso de la explotación laboral de menores de Unilever en India ${ }^{77}$, el de Trafigura en relación con el vertido ilegal de residuos tóxicos en Costa de Marfil $^{78}$ o el presente caso de estudio, Dutch Shell Nigeria. Estos casos han planteado algunas cuestiones interesantes desde el punto de visto legal; por una parte, la responsabilidad de las empresas matrices (parent company) holandesas por la participación de sus filiales en violaciones de derechos fundamentales ${ }^{79} \mathrm{y}$, por otra, si la ley holandesa debería proporcionar mecanismos legales para las víctimas en el extranjero ${ }^{80}$.

reparar a las víctimas de violaciones de los derechos humanos. Según el Tribunal de Apelaciones para el Segundo Circuito de los Estados Unidos, las personas jurídicas no pueden ser consideradas sujetos de responsabilidad internacional pasiva en eventos de inobservancia del ius cogens en el ámbito de los derechos humanos por cuanto no existe evidencia de práctica internacional al respecto. Por lo tanto, el tribunal concluyó que la acción presentada bajo el ATCA no tenía fundamento en la medida en que esa legislación solo puede ser utilizada cuando se trata de violaciones de normas del derecho internacional que son específicas, universales y obligatorias. CÉSPEDES-BÁEZ, L. M., "Derechos humanos y responsabilidad de las personas jurídicas privadas: Una tarea pendiente", Revista de la Fundación para el Debido Proceso, vol. 4 núm. 15, 2011. Véase Kiobel, et al. v. Royal Dutch Petroleum Co., et al, de: http://www.ca2.uscourts.gov/decisions/isysquery/6af680f7-684f-4470-8c6a-15870801f72f/5/doc/064800-cv_opn.pdf.

${ }^{76}$ Existe una extensa literatura en relación con el caso Kiobel vs. Royal Dutch Shell Petroleum llevado bajo la jursidicción del ATCA. Véase KEITNER, CH., "Kiobel v. Royal Dutch Corp., Another Round in the Fight Over Corporate Liability Under the Alien Tort Statute", ASIL Insight, vol. 14, núm. 30, 2010; THEOPHILA, M., "Moral Monsters Under the Bed: Holding Corporations Accountable for Violations of the Alien Tort Statute After Kiobel v. Royal Dutch Petroleum Co.”, Fordham Law Review, vol. 79, 2011; STANISZ, J. M., "The Expansion of Limited Liability Protection in the Corporate Form: The Aftermath of Kiobel v. Royal Dutch Petroleum Co.”, Brooklin J. of Corporate, Financial \& Commercial Law, 2011; BELLIA A. J. y CLARK, B. R., "Kiobel, Subject Matter Jurisdiction, and the Alien Tort Statute", Notre Dame Legal Studies Research Paper, núm. 12-52.

77 JÄGERS, N.M.C.P. y VAN DER HEIJDEN, M. J., "Corporate Human Rights Violations: The Feasibility of Civil Recourse in The Netherlands", Brooklyn Journal of International Law, vol. 33, núm. 3, 2008 .

${ }^{78}$ Véase Trafigura Beheer B.V., de: http://www.evb.ch/cm_data/Trafigura_e.pdf.

${ }^{79}$ En este sentido, CASTERMANS y VAN DER WIEDE se cuestionan si una empresa holandesa puede ser considerada responsable por la participación de su filial en una violación de derechos fundamentales reconocidos internacionalmente como son los derechos humanos. Y, si es así, ¿quién determina la responsabilidad de la empresa matriz? CASTERMANS, A.G. y VAN DER WEIDE, J. (2010, 17 de junio), "The legal liability of Dutch parent companies for subsidiaries' involvement in violations of 
Varios países han mostrado un gran progreso en los recursos civiles para las víctimas de los daños ocasionados por las operaciones de empresas multinacionales ${ }^{81}$, en especial, Australia, Canadá, Reino Unido, Estados Unidos y Holanda ${ }^{82}$. Este último país es de gran interés no solo para los académicos y los litigantes, sino también para los responsables de diseñar políticas debido a que proporcionó un foro para reclamar compensaciones por los abusos de una filial de una empresa holandesa en el extranjero ante los tribunales del país de origen ${ }^{83}$.

En el derecho civil holandés las empresas tienen personalidad legal y pueden ser demandadas ${ }^{84}$ con el fin de reparar los daños sufridos por otras personas a consecuencia de un acto ilegal imputable a ellas ${ }^{85}$. Por su parte, la Ley de Enjuiciamiento Civil holandesa contiene algunas excepciones que reconocen la competencia internacional de sus tribunales. Estas disposiciones, combinadas con las reglas holandesas de derecho internacional privado y su cultura legal, hacen factible el litigio transnacional en este país $^{86}$. Cabe resaltar lo particular de la competencia internacional de sus tribunales, en especial en el caso de estudio, que se convierte en el primero de su tipo, en el que un tribunal determinó que era competente para conocer no solo de las demandas contra una empresa matriz con sede en La Haya, sino también de las reclamaciones contra su filial en Nigeria. La singularidad del caso es que, a diferencia de los Estados Unidos, este país no cuenta con un instrumento jurídico equivalente al ATCA que ofrezca una vía jurídica para compensar a las víctimas de los abusos de las empresas, sobre todo por violaciones de derechos humanos ${ }^{87}$. A pesar de este hecho, como JÄGERS (et. ál.) señala, varias

fundamental, internationally recognised rights". Consultado el 8 de abril de 2014, de: http://ssrn.com/abstract=1626225.

${ }^{80}$ JÄGERS, N.M.C.P. y VAN DER HEIJDEN, M. J., “Corporate...” cit., p. 840.

${ }^{81}$ PIGRAU, A., BORRÀS, S., JARIA, J. y CARDESA-SALZMANN, A., “The Interplay...” cit., p. 1.

${ }^{82}$ ENNEKING, L. (a), "The Future of Foreign Direct Liability? Exploring the International Relevance of the Dutch Shell Nigeria Case", Utrecht Law Review, vol. 10, núm. 1, 2014.

${ }^{83}$ ENNEKING, L. (b), Foreign direct liability and beyond. Exploring the role of tort law in promoting international corporate social responsibility and accountability, Eleven International Publishing, La Haya, 2012.

84 Véase artículo 2.3 del Código Civil holandés: “Associations ('verenigingen'), Cooperatives ('coöperaties'), Mutual Insurance Societies ('onderlinge waarborgmaatschappijen'), Open Corporations*) ('naamloze vennootschappen'), Closed Corporations**) besloten vennootschappen') and Foundations ('stichtingen') have legal personality".

${ }^{85}$ Véase artículo 6.162 (1) del Código Civil holandés.

${ }^{86}$ JÄGERS, N.M.C.P. y VAN DER HEIJDEN, M. J., “Corporate...” cit., p. 840.

${ }^{87}$ Ibidem, p. 838. 
sentencias recientes en Holanda muestran que sus tribunales pueden tener una competencia de alcance extraterritorial ${ }^{88}$.

\section{La demanda contra Shell en Holanda}

En mayo de 2008, cuatro agricultores y pescadores residentes en el delta del Níger, junto con Milieudefensie y Amigos de la Tierra Nigeria ${ }^{89}$, interpusieron acciones de orden civil contra la empresa matriz Royal Dutch Shell PLC y su filial en Nigeria, Shell Development Company Petroleum, ante el Tribunal de Distrito de La Haya en Holanda por los daños sufridos a causa de los diversos casos de contaminación ocasionados por los vertidos de petróleo de la empresa en tres aldeas distintas: Oruma, Goi e Ikot Ada Udo. Los vertidos alegados no solo afectaban a las principales fuentes de sustento de los demandantes, sino que también suponían considerables problemas de salud para las personas. Por una parte, la acusación principal contra la empresa matriz se basaba en la falta de supervisión de su filial nigeriana en cuanto al cumplimiento adecuado de los estándares para la extracción de petróleo contemplados en las políticas ambientales del grupo corporativo ${ }^{90}$, cuestión que no solo podía abordar la empresa matriz, sino que también debía hacerlo ${ }^{91}$. Según los demandantes, la falta de supervisión sobre la filial es la causa de que los vertidos ocurrieran o, al menos, de que no fueran detenidos a tiempo ${ }^{92}$. Por otra, la acusación principal contra la filial nigeriana fue la falta de la debida diligencia en la prevención de los vertidos de petróleo ocurridos, no haber tomado las medidas adecuadas para mitigar sus consecuencias y no limpiar

\footnotetext{
Netherlands, ICJ, Ginebra, 2010.

${ }^{90}$ ENNEKING, L. (a), "The Future..." cit., p. 45.

${ }^{91}$ GARCÍA ÁLVAREZ, L., "Daños...” cit., p. 554.

${ }^{92}$ Ibídem.
}

${ }^{88}$ JÄGERS, N., JESSE, K. y VERSCHUUREN, J., “The Future...” cit., p. 36.

${ }^{89}$ En Holanda, como en otros países, las organizaciones no gubernamentales (ONG) han sido las encargadas de emprender acciones contra las empresas multinacionales que operan en países en desarrollo. Las ONG pueden intervenir mediante una acción colectiva (class actions) contemplada en el artículo 3:305(a) del Código Civil holandés, que establece que la organización que pretenda llevar acciones contra alguna empresa deberá intentar resolver el asunto mediante un acuerdo con el demandado antes de comenzar el litigio. No obstante, la desventaja de esta acción es que las organizaciones no pueden pedir la compensación, ya que es un derecho que solo está previsto para las víctimas, de forma individual, que han sufrido los daños. A pesar de esto, la acción colectiva representa un esfuerzo importante para responsabilizar a las empresas, ya que en muchas ocasiones este tipo de acciones conllevan campañas a cargo de las ONG, lo cual supone una presión para las empresas y puede influir en su comportamiento. ICJ, Access to Justice: Human Rights Abuses Involving Corporations - The 
correctamente los sitios contaminados por los vertidos, obligación que está estipulada en la legislación nigeriana con independencia de la causa del vertido ${ }^{93}$. Debido a la naturaleza jurídica de las empresas multinacionales, resulta especial que la acción interpuesta se dirija tanto a la empresa matriz como a su filial. Por lo general, la empresa matriz, que ejerce control sobre un número de filiales constituidas conforme a la legislación de los Estados en los que operan, posee una personalidad jurídica autónoma e independiente de sus filiales. Por lo tanto, estas últimas están sujetas a la jurisdicción y a las leyes de los países en que están constituidas y en los que operan ${ }^{94}$. Según los demandantes, en el caso de estudio existe una clara vinculación entre ambas empresas; por una parte, Royal Dutch Shell PLC es propietaria de Shell Development Company Petroleum y, por otra, recibe una cuota de los beneficios de sus filiales ${ }^{95}$. Por lo tanto, las políticas ambientales del grupo corporativo habrían de influir, en mayor o menor grado, en las filiales que operan en diferentes países del mundo.

Entre las peticiones de la parte demandante se encuentran, inter alia, la declaración de responsabilidad de ambas empresas — matriz y filial— por los daños sufridos; la responsabilidad de las empresas ante Milieudefensie por los daños ambientales; la obligación de las empresas de reemplazar el viejo oleoducto; la limpieza del suelo del petróleo vertido y la purificación del agua; y un mejor mantenimiento de los oleoductos bajo su administración para evitar nuevos vertidos en el futuro, entre otras ${ }^{96}$. Por su parte, Shell en la contestación negó la comisión de errores y la responsabilidad de Royal Dutch Shell PLC por cualquier actividad de su filial. Posteriormente, antes de dictarse la resolución sobre el fondo del asunto, la empresa impugnó en varias ocasiones la competencia del tribunal holandés para conocer del asunto (13 de mayo y 30 de diciembre de 2009) ${ }^{97}$, cuestión que el tribunal desestimó en la resolución interlocutoria y final del asunto.

\footnotetext{
${ }^{93}$ Véase Environmental Guidelines and Standards for the Petroleum Industry in Nigeria (EGASPIN), edición revisada 2002, sección 4.1: "An operator shall be responsible for the containment and recovery of any spill discovered within his operational area, whether or not its source is known".

${ }^{94}$ BORRÁS PENTINAT, S. y VILASECA BOIXAREU, I., “Los conflictos...” cit., pp. 140-143.

${ }^{95}$ GARCÍA ÁLVAREZ, L., "Daños...” cit., p. 554.

${ }^{96}$ Véase sentencia del Tribunal de Distrito de La Haya del 30 de enero de 2013, C/09/337050/ HA ZA 09-1580, Friday Alfred Akpan \& Milieudefensie, c. Royal Dutch Shell plc \& Shell Petroleum Development Company of Nigeria. Párrafo 3.1, de: http://www.menschenrechte.uzh.ch/entscheide/Friday_Alfred.pdf.

${ }^{97}$ GARCÍA ÁLVAREZ, L., “Daños...” cit., p. 558.
} 


\subsection{Competencia judicial}

Mediante sentencia interlocutoria de $2009^{98}$, el Tribunal de Distrito de La Haya determinó que era competente para conocer de la demanda contra Royal Dutch Shell PLC en La Haya y su filial nigeriana Shell Development Company Petroleum. La competencia de los tribunales holandeses estriba no solo en el sistema legal holandés, sino también en las normas de armonización de la competencia judicial de la Unión Europea (UE) contempladas en el Reglamento (CE) núm. 44/2001 ${ }^{99}$ (Bruselas I) $^{100}$, refundido por el Reglamento (UE) núm. 1215/2012 del Parlamento Europeo y del Consejo, de 12 de diciembre de 2012, relativo a la competencia judicial, el reconocimiento y la ejecución de resoluciones judiciales en materia civil y mercantil ${ }^{101}$. El objeto del Reglamento Bruselas I es regular los conflictos entre los tribunales nacionales de los Estados miembros de la UE basándose en el principio de forum rei; sus normas son obligatorias y privan a los tribunales nacionales de cualquier discrecionalidad para conocer de una demanda si no es de acuerdo con lo previsto en el Reglamento $^{102}$. Por lo tanto, bajo el régimen de Bruselas I los tribunales holandeses, en principio, tendrán jurisdicción sobre casos civiles transnacionales en los que figure como demandada una empresa que tenga su domicilio (sede estatutaria, administración central y/o centro de actividad principal) en Holanda ${ }^{103}$, sin poder declinar la jurisdicción sobre la base de doctrinas discrecionales como la del forum non

98 Véase sentencia interlocutoria del Tribunal de Distrito de La Haya del 30 de diciembre de 2009,
ECLI $N L \cdot R B S G R \cdot 2009 \cdot B K 8616$, http://uitspraken.rechtspraak.nl/inziendocument?id=ECLI:NL:RBSGR:2009:BK8616.

99 Véase Reglamento CE núm. 44/2001, relativo a la competencia judicial, el reconocimiento y la ejecución de resoluciones judiciales en materia civil y mercantil, de: http://eurlex.europa.eu/LexUriServ/LexUriServ.do?uri=CONSLEG:2001R0044:20081204:ES:PDF.

${ }^{100}$ El Reglamento (CE) núm. 44/2001 es considerado la versión europea del ATCA ya que proporciona la posibilidad de litigar ante tribunales europeos contra las empresas domiciliadas en la UE por los daños que se producen en un tercer país. No obstante, existen divergencias entre ambos instrumentos jurídicos; JÄGERS y VAN DER HEIJDEN señalan algunas de las diferencias y destacan que el alcance del Reglamento (CE) núm. 44/2001 es más amplio en comparación con el ATCA, ya que este último solo es aplicable a los extranjeros. No obstante, en relación con las empresas, el Reglamento es más limitado que el ATCA debido a que solo se aplica a las empresas registradas o domiciliadas en la UE. JÄGERS, N.M.C.P. y VAN DER HEIJDEN, M. J., “Corporate...” cit., pp. 847-848.

${ }^{101}$ Véase Reglamento (UE) núm. 1215/2012 del Parlamento Europeo y del Consejo, de 12 de diciembre de 2012, relativo a la competencia judicial, el reconocimiento y la ejecución de resoluciones judiciales en materia civil y mercantil, de: http://www.boe.es/doue/2012/351/L00001-00032.pdf.

${ }^{102}$ VAN DER HEIJDEN, M. J., Transnational... cit., p. 86.

${ }^{103}$ ENNEKING, L. (b), Foreign... cit., pp. 318-320. 
conveniens $^{104}$. La adopción del Reglamento Bruselas I en Holanda sirvió como guía para la revisión de la Ley de Enjuiciamiento Civil holandesa ${ }^{105}$.

Por una parte, el Tribunal de Distrito ${ }^{106}$ señaló su competencia para conocer de las reclamaciones contra Royal Dutch Shell PLC de conformidad con el artículo 2.1 y 60.1 del Reglamento Bruselas I ${ }^{107}$; el artículo 2.1 establece que "las personas domiciliadas en un Estado miembro estarán sometidas, sea cual fuere su nacionalidad, a los órganos jurisdiccionales de dicho Estado". La noción de domicilio en relación con una persona jurídica se contempla en el artículo 60.1: “[...] se entenderá que una sociedad u otra persona jurídica está domiciliada en el lugar en que se encuentre: a) su sede estatutaria; b) su administración central; c) su centro de actividad principal”. Por su parte, en el sistema holandés, de manera similar al Reglamento Bruselas I, la noción de domicilio de una empresa es entendida como su lugar de constitución (principle of incorporation $)^{108}$. En comparación con el ATCA, la doctrina holandesa de constitución de una empresa que fija la competencia de los tribunales es mucho más estricta, ya que bajo el ATCA se puede determinar la competencia internacional sobre casos relacionados con individuos temporalmente presentes en los Estados Unidos o sobre las corporaciones que hacen negocios en el país, es decir, la exigencia de vinculación no es tan estricta ${ }^{109}$. Sobre esta base, algunas empresas extranjeras han sido llevadas ante los

\footnotetext{
${ }^{104}$ Según JÄGERS y VAN DER HEIJDEN, la doctrina del forum non conveniens representa un obstáculo legal importante para los demandantes, especialmente en el litigio bajo las disposiciones del ATCA. A través de esta doctrina, los tribunales pueden desestimar los casos si se demuestra que existe un foro más adecuado para el litigio. Se recurre a esta doctrina principalmente en los países del sistema del common law como el Reino Unido o los Estados Unidos. Por el contrario, esta doctrina no se emplea de la misma forma en Holanda y no se puede rechazar el ejercicio de la jurisdicción de los tribunales sobre su base. Esto se ha reflejado en el caso de estudio, donde el tribunal holandés señaló que actualmente el forum non conveniens ya no juega ningún papel en el derecho internacional. JÄGERS, N.M.C.P. y VAN DER HEIJDEN, M. J., "Corporate..." cit., pp. 849-850.

${ }^{105}$ Ibídem p. 845.

${ }^{106}$ Véase párrafo 4.1 de la Sentencia del Tribunal de Distrito de La Haya de 30 de enero de 2013.

${ }^{107}$ VAN DER HEIJDEN, M. J., Transnational... cit., p. 104.

${ }^{108}$ JÄGERS, N.M.C.P. y VAN DER HEIJDEN, M. J., “Corporate...” cit., p. 845.

${ }^{109}$ Entre las diversas acciones interpuestas contra Shell se encuentra el caso Wiwa vs. Royal Dutch Petroleum Corp., al amparo del ATCA. En este caso, los demandantes alegaron que la compañía Shell Nigeria había ayudado a los militares nigerianos a torturar a Ken Saro Wiwa y otros particulares en 1995. Según los demandantes, la empresa matriz Royal Dutch Shell PLC (Holanda) y Shell Transport and Trading (Reino Unido) controlaban las acciones de Shell Nigeria, por lo que los actos de Shell Nigeria debían ser considerados como de las sociedades demandadas y atribuidos a ellas. En consecuencia, el tribunal determinó el ejercicio de la jurisdicción de los Estados Unidos sobre la base de dos motivos: la cotización de ambas empresas en la Bolsa de Nueva York y al hecho de que los demandados mantuvieran en el país una oficina para las relaciones con los inversores. REQUEJO ISIDRO, M., "Responsabilidad civil y derechos humanos en EEUU: ¿el fin del ATS?”, InDret Revista para el Análisis del Derecho, núm. $3,2011$.
} 
tribunales de los Estados Unidos por las violaciones de derechos humanos ocurridas en un país tercero, y los tribunales han aceptado como suficiente para conocer del asunto un vínculo mínimo entre el demandado y la jurisdicción de los Estados Unidos ${ }^{110}$.

Por otra, la competencia internacional de los tribunales holandeses para conocer de las reclamaciones sobre la filial de Shell en Nigeria suscita cuestiones interesantes a analizar ya que, en principio, el tribunal holandés no tiene competencia sobre una filial en el extranjero. Sin embargo, de acuerdo con el artículo 4.1 del Reglamento Bruselas I, "si el demandado no estuviere domiciliado en un Estado miembro, la competencia judicial se regirá, en cada Estado miembro, por la ley de este Estado miembro". Por lo tanto, en el caso de estudio la competencia sobre la filial en Nigeria se determinó de acuerdo con lo establecido en el artículo $7.1^{111}$ de la Ley de Enjuiciamiento Civil holandesa, que señala que, en caso de que un tribunal holandés tenga competencia sobre uno de los acusados en cuestiones iniciadas por una demanda, también tendrá competencia sobre los otros acusados en el mismo proceso siempre que las distintas acusaciones estén conectadas hasta tal punto que por razones de eficiencia justifiquen una audiencia conjunta (joint hearing). En este sentido, ENNEKING señala que los tribunales holandeses pueden asumir competencia sobre las reclamaciones de responsabilidad en contra de empresas extranjeras si dichas reclamaciones están estrechamente relacionadas con otras similares en contra de una empresa constituida en Holanda y/o con sede en el país ${ }^{112}$. Por consiguiente, de acuerdo con la disposición del artículo 7.1, se tiene competencia sobre ambas empresas sin la necesidad del levantamiento del velo corporativo, el cual no está previsto en el Reglamento Bruselas I, lo que deja una laguna legal en relación con los demandados (empresas) no domiciliados en un Estado miembro, ya que de otra manera el principio de responsabilidad limitada determinaría la incompetencia para conocer de las reclamaciones sobre la filial ${ }^{113}$.

En relación con la competencia judicial del tribunal holandés para conocer del asunto, Shell alegó que el reconocimiento de la competencia por parte del tribunal se realiza sobre una base legal incorrecta. Según la empresa, bajo la ley nigeriana era previsible

\footnotetext{
110 Ídem.

${ }^{111}$ Véase artículo 7.1 de la Ley de Enjuiciamiento Civil holandesa.

${ }^{112}$ ENNEKING, L. (b), Foreign... cit., pp. 319-320.

${ }^{113}$ GARCÍA ÁlVAREZ, L., “Daños...” cit., p. 560.
} 
que la demanda contra Royal Dutch Shell PLC no prosperara; en consecuencia, los demandantes incurrían en un abuso procesal al demandar en conjunto a la empresa matriz y a su filial para fijar la competencia sobre la matriz y aplicar lo dispuesto en el artículo $7.1^{114}$. Este argumento fue desestimado por el tribunal holandés, que señaló que no existe ningún abuso procesal ya que bajo ciertas circunstancias, sobre la base de la legislación nigeriana, la empresa matriz de una filial puede ser responsable por negligencia cuando el daño sufrido por las personas sea consecuencia de las actividades de dicha filial ${ }^{115}$. Situación que se presenta en el caso inglés Chandler vs. Cape PLC, según señaló el tribunal ${ }^{116}$. Asimismo, para objetar la competencia del tribunal, la empresa invocó la sentencia del asunto Panier ${ }^{117}$ del Tribunal de Justicia de la Unión Europea (TJUE) con el fin de condicionar la aplicación del artículo 7.1 a la posibilidad de la filial de prever que pueda ser juzgada en Holanda por sus actividades en Nigeria. En analogía con lo señalado por el TJUE para la aplicación del artículo 6.1 del Reglamento Bruselas I, se requería que los demandados pudieran haber previsto la posibilidad de ser juzgados en un Estado miembro en el que al menos uno de ellos estuviera domiciliado en casos en donde existe una diferencia en la base de las demandas iniciadas contra varios $\operatorname{acusados}^{118}$. Según los demandados, Shell Development Company Petroleum no podía prever el hecho de ser juzgada en Holanda, y, en consecuencia, el tribunal no debía aplicar el artículo 7.1 para conocer sobre las reclamaciones a la filial. Esta alegación fue desestimada por el tribunal sobre la base de que la demanda contra la matriz y la filial tienen (en parte) la misma base legal, que es la responsabilidad por negligencia ${ }^{119}$. Igualmente, señaló que sí era previsible que la filial pudiera ser juzgada en Holanda junto con la matriz de acuerdo con la tendencia internacional antes señalada de responsabilizar a las empresas matrices en su propio país por las prácticas dañosas junto con sus filiales ${ }^{120}$, tendencia que no ha encontrado cabida

\footnotetext{
${ }^{114}$ Véase párrafo 4.2 de la Sentencia del Tribunal de Distrito de La Haya de 30 de enero de 2013.

${ }^{115}$ Véase párrafo 4.3 ibídem.

116 Ídem.

${ }^{117}$ Véase Sentencia del Tribunal de Justicia de la Unión Europea (Sala 3. ${ }^{\text {a }}$ ) de 1 de diciembre de 2011, Eva-Maria Painer v. Standard Verlags GmbH y otros, asunto C-145/10, de: http://curia.europa.eu/juris/document/document.jsf?text=\&docid=115785\&pageIndex=0\&doclang=es\&m ode $=$ req \&dir $=\&$ occ $=$ first $\&$ part $=1 \& \operatorname{cid}=387499$.

${ }^{118}$ Véase párrafo 4.4 de la Sentencia del Tribunal de Distrito de La Haya de 30 de enero de 2013.

119 JÄGERS, N., JESSE, K. y VERSCHUUREN, J., “The Future...” cit., p. e39.

${ }^{120}$ Véase párrafo 4.4 de la Sentencia del Tribunal de Distrito de La Haya de 30 de enero de 2013.
} 
en la agenda política de la UE ya que, a pesar de que se ha contemplado la incorporación en el Reglamento Bruselas I de disposiciones que permitan la competencia de los tribunales en asuntos con demandados no domiciliados en un Estado miembro, estas no han sido incorporadas en el Reglamento (UE) núm. 1215/2012, que refunde Bruselas I.

Cabe señalar que la legislación holandesa contempla el forum necessitatis para casos excepcionales $^{121}$. Por ejemplo, casos en los que el procedimiento en el extranjero pueda ser imposible ya que no hay tribunal con competencia o porque el acceso al tribunal en el extranjero no es posible debido a desastres naturales o guerras; casos en que el demandante pertenece a un determinado grupo de población que sufre discriminación social y legal en el país del tribunal competente ${ }^{122}$; o situaciones en las que no se puede esperar un juicio justo a nivel local debido a que las autoridades locales participan, de una u otra manera, en las actividades locales nocivas y/o contribuyen para que se lleven a cabo $^{123}$. Sin embargo, pocos casos se han llevado ante la jurisdicción holandesa de conformidad con los supuestos señalados ${ }^{124}$. La incorporación del forum necessitatis en el Reglamento Bruselas I es otra cuestión que ha sido discutida desde la UE con el fin de proporcionar competencia a los tribunales de la UE en determinadas circunstancias, como en demandas civiles contra empresas no domiciliadas en un Estado miembro ${ }^{125}$, es decir, cuando ninguno de los criterios del artículo 2.1 y 60.1 del Reglamento conceda competencia a los tribunales de un Estado miembro; o cuando exista un riesgo de que las víctimas puedan ser privadas de su derecho a acceder a la justicia ${ }^{126}$. No obstante,

\footnotetext{
${ }^{121}$ CASTERMANS, A.G. y VAN DER WEIDE, J. (2010, 17 de junio), “The legal...” cit., pp. 45-46.

${ }^{122}$ Véase artículo 9.c de la Ley de Enjuiciamiento Civil holandesa.

${ }^{123}$ ENNEKING, L. (b), Foreign... cit., p. 320.

${ }^{124}$ VAN DER HEIJDEN, M. J., Transnational... cit., p. 118.

${ }^{125}$ ENNEKING, L. (b), Foreign... cit., p. 150.

${ }^{126}$ En relación con el forum necessitatis, la Comisión, en su propuesta para refundir el Reglamento (CE) núm. 44/2001, contempló que se pudiese actuar contra "un demandado con domicilio en un tercer país en el lugar en que estén sitos sus bienes muebles, siempre que su valor no sea desproporcionado en relación con la cuantía de la demanda, y que el litigio tenga una vinculación suficiente con el Estado miembro del tribunal al que se somete el asunto. Además, los tribunales de un Estado miembro podrán ejercer su competencia si no existe ningún otro foro que garantice el derecho a un juicio justo y si el conflicto tiene una vinculación suficiente con el Estado miembro concernido (forum necessitatis)". Véase COM (2010) 748 (Bruselas), Propuesta de Reglamento del Parlamento Europeo y del Consejo relativo a la competencia judicial, el reconocimiento y la ejecución de resoluciones judiciales en materia civil y mercantil \{SEC (2010) 1547$\} \quad\{$ SEC $\quad(2010) \quad 1548\}, \quad$ de: lex.europa.eu/LexUriServ/LexUriServ.do?uri=COM:2010:0748:FIN:ES:PDF\#page=2.
} 
esta disposición tampoco se ha incorporado en el Reglamento núm. 1215/2012, que refunde al Reglamento Bruselas I ${ }^{127}$.

Por lo tanto, la competencia del tribunal de Holanda sobre la filial en el extranjero de las empresas multinacionales en el caso de estudio, mediante la aplicación de lo previsto en el artículo 7.1 de la Ley de Enjuiciamiento Civil holandesa, se presenta de forma excepcional en la UE debido a la falta de disposiciones que permitan a los tribunales conocer de asuntos de un demandado no domiciliado en un Estado miembro. Por consiguiente, secundando lo que señala GARCÍA ÁLVAREZ en relación con la competencia de los tribunales sobre casos por daños ambientales ocasionados en terceros Estados por filiales de matrices domiciliadas en la UE, "la mejor solución sería una norma de Derecho material uniforme [...] que facilite que las sociedades matrices pertenecientes a grupos multinacionales respondan por los daños a la salud y al patrimonio como consecuencia de los daños ambientales causados por actividades de sus filiales siempre y cuando aquéllas hayan intervenido, aunque indirectamente, en su materialización $[\ldots]^{1,128}$.

\subsection{Ley aplicable}

Una vez establecida la competencia de los tribunales holandeses para conocer del caso de estudio, es pertinente abordar la cuestión en relación con la ley aplicable al caso. Desde el ámbito de la UE, los tribunales de los Estados miembros tendrán que determinar el derecho aplicable a la reclamación medioambiental presentada a través de lo establecido en el Reglamento (CE) núm. 864/2007, relativo a la ley aplicable a las obligaciones extracontractuales, más conocido como Roma II ${ }^{129}$. Según este reglamento, por regla general la ley aplicable, en situaciones que impliquen un conflicto de leyes, es

\footnotetext{
${ }^{127}$ OTERO GARCÍA-CASTRILLÓN, C., "EL DIPr de la UE en la determinación de la responsabilidad civil por daños al medio ambiente", Anuario Hispano-Luso-Americano de Derecho Internacional, 20132014.

${ }^{128}$ GARCÍA ÁlVAREZ, L., “Daños...” cit., p. 567.

${ }^{129}$ El Reglamento (CE) núm. 864/2007 se aplica a las obligaciones extracontractuales en materia civil y mercantil en aquellas situaciones en que exista un conflicto de leyes. El ámbito de aplicación territorial del Reglamento es universal, rige tanto en conflictos de leyes entre Estados miembros de la UE como entre Estados miembros y países terceros. La ley determinada por el Reglamento será la aplicable al asunto, ya sea la ley de un Estado miembro o la de un tercer Estado. Véase el Reglamento (CE) núm. 864/2007, relativo a la ley aplicable a las obligaciones extracontractuales, de: http://eurlex.europa.eu/LexUriServ/LexUriServ.do?uri=OJ:L:2008:177:0006:0016:ES:PDF. Consultado el 2 de marzo de 2014.
} 
la del Estado donde se ha producido el daño ${ }^{130}$, es decir opera el principio lex loci damni ${ }^{131}$, con algunas excepciones a la aplicación de este principio como es el caso de la libertad de elección de las partes para convenir la ley aplicable al asunto mediante un acuerdo posterior al hecho generador del daño ${ }^{132}$.

En casos relacionados con daños al medio ambiente, el Reglamento Roma II incorpora el principio "quien contamina paga" y otorga la posibilidad a los demandados de elegir la ley aplicable, adoptando el principio de lex loci damni o el principio de lex loci delicti $^{133}$. En este sentido, el artículo 7 del Reglamento Roma II establece que "la ley aplicable a la obligación extracontractual que se derive de un daño medioambiental o de un daño sufrido por personas o bienes como consecuencia de dicho daño, será la ley determinada en virtud del artículo 4, apartado 1, a menos que la persona que reclama el resarcimiento de los daños elija basar sus pretensiones en la ley del país en el cual se produjo el hecho generador del daño". Se entiende por daños ambientales "el cambio adverso de un recurso natural, como el agua, el suelo o el aire, el perjuicio a una función que desempeña ese recurso natural en beneficio de otro recurso natural o del público, o un perjuicio a la variabilidad entre los organismos vivos"134. Esto incluye tanto el daño ecológico puro como los daños ambientales que afectan a particulares y/o a su patrimonio $^{135}$. Sin embargo, los daños nucleares quedan excluidos de acuerdo con lo establecido en el artículo 1.2.f ${ }^{136}$. Por otro lado, el Reglamento no hace referencia a "víctimas", sino a "persona que reclama el resarcimiento de los daños","137, lo que puede suponer que el demandante sea un individuo o una persona jurídica, pública o privada $^{138}$. Finalmente, en relación con la elección de la ley aplicable, ENNEKING señala que el objeto principal de la disposición del artículo 7 del Reglamento Roma II es elevar el nivel general de protección del medio ambiente dando a la víctima de los

\footnotetext{
${ }^{130}$ ENNEKING, L. (b), Foreign... cit., p. 214.

${ }^{131}$ Véase artículo 4.1 del Reglamento (CE) núm. 864/2007.

${ }^{132}$ Véase artículo 14.1.a del Reglamento (CE) núm. 864/2007.

133 JÄGERS, N.M.C.P. y VAN DER HEIJDEN, M. J., “Corporate...” cit., p. 853.

${ }^{134}$ Véase considerando 24 del Reglamento (CE) núm. 864/2007.

${ }^{135}$ OTERO GARCÍA-CASTRILLÓN, C., “EL DIPr...” cit., pp.18-19.

${ }^{136}$ Véase artículo 1.2.f del Reglamento (CE) núm. 864/2007.

${ }^{137}$ Véase considerando 25 del Reglamento (CE) núm. 864/2007.

${ }^{138}$ OTERO GARCÍA-CASTRILLÓN, C., "EL DIPr...” cit., p. 19.
} 
daños ambientales la oportunidad de elegir la ley más favorable ${ }^{139}$. En especial en un contexto de Norte-Sur en el que las normas ambientales suelen ser más protectoras en países desarrollados que en los países en desarrollo donde operan las filiales de las empresas multinacionales domiciliadas en el Norte. Asimismo, el sistema jurídico de los Estados de origen (home States) de las empresas multinacionales puede que ofrezca mejores condiciones para los demandantes del Estado anfitrión para llevar acciones legales contra las empresas multinacionales ${ }^{140}$. Por ejemplo, desde una perspectiva de los derechos humanos, la Comisión Internacional de Juristas (CIJ) ha señalado que la legislación holandesa podría ser más precisa a la hora de regular la responsabilidad por violaciones de los derechos humanos y tener normas más estrictas en materia de debida diligencia en relación con las empresas ${ }^{141}$.

No cabe duda de que las víctimas de daños ambientales podrían beneficiarse del régimen de Roma II en los litigios transnacionales contra empresas multinacionales al tener la posibilidad de elegir la ley del Estado de origen de estas, teniendo en cuenta que estos Estados suelen presentar mejores vías para la reparación que los Estados donde se produjeron los daños. En el caso de estudio, habría habido la posibilidad de elegir la legislación holandesa por parte de las víctimas como la ley aplicable al caso; sin embargo, debido a que los hechos ocurrieron antes del 11 de enero de $2009^{142}$, el régimen de Roma II no se aplica al caso. Por lo tanto, el tribunal holandés concluyó que la ley aplicable se ha de determinar con arreglo al derecho internacional privado holandés ${ }^{143}$, especialmente de conformidad con el Act of 11th April 2001 on Conflicts of Law in Tort ${ }^{144}$ (Wet Conflictenrecht Onrechtmatige Daad [WCOD]) ${ }^{145}$. JÄGERS y VAN DER HEIJDEN señalan que, bajo la ley holandesa, las partes pueden elegir la ley

\footnotetext{
139 La autora señala que "the environmental damage rule's aim is to raise the general level of environmental protection by giving the victim of environmental harm the opportunity to choose the most favourable law". ENNEKING, L. (b), Foreign... cit., p. 214.

${ }^{140}$ En este sentido, ENNEKING señala que "the Western society home country system of tort law will in these cases generally be more favourable to the host country plaintiffs than the host country system of tort law where it comes to levels of protection and levels of damages[...]". Ibídem, p. 216.

${ }^{141}$ ICJ, Access... cit., p. 21.

${ }^{142}$ Fecha en que entró en vigor el Reglamento (CE) núm. 864/2007, relativo a la ley aplicable a las obligaciones extracontractuales.

${ }^{143}$ Véase párrafo 4.8 de la Sentencia del Tribunal de Distrito de La Haya de 30 de enero de 2013.

144 Véase Act of 11th April 2001 on Conflicts of Law in Tort, de: http://wetten.overheid.nl/BWBR0012408/geldigheidsdatum_14-09-2011.

${ }^{145}$ Véase párrafo 4.8 de la Sentencia del Tribunal de Distrito de La Haya de 30 de enero de 2013.
} 
aplicable según el artículo 6 (1) del WCOD ${ }^{146}$; al igual que en el Reglamento Roma II, la elección de la ley aplicable podrá ser convenida por las partes mediante un acuerdo en el que se establezca la ley que regirá en caso de conflicto ${ }^{147}$. No obstante, conforme a la jurisprudencia holandesa, la regla principal de la ley aplicable se fija sobre la base del principio de lex loci damni. La aplicación de este principio se determina de acuerdo con el lugar del hecho generador del daño (Handlungsort) y el lugar en que los daños se manifiestan (Erfolgsort) ${ }^{148}$. La multiplicidad de locus tiende a presentarse primordialmente en casos relativos a contaminación transfronteriza ${ }^{149}$, al igual que en casos donde una empresa multinacional opera en el extranjero (caso Dutch Shell Nigeria), donde el Handlungsort y el Erfolgsort son diferentes ubicaciones. En situaciones de multiplicidad de locus se aplica el artículo 3 (2) del WCOD $^{150}$, lo que implica que, cuando el daño se manifiesta en un lugar distinto de donde se llevó a cabo el hecho generador del daño, la ley aplicable será aquella donde el daño y sus efectos se han manifestado, a menos que el demandado no pudiera prever razonablemente este efecto perjudicial.

Por consiguiente, considerando los hechos y los daños que tuvieron lugar en Nigeria, el tribunal holandés concluyó, de acuerdo con lo estipulado en los artículos 3 (1) y 3 (2) del WCOD, que las pretensiones de la demanda principal deben ser evaluadas sustantivamente de conformidad con el derecho nigeriano, en particular, la ley del estado de Akwa Ibom, donde ocurrieron los vertidos de petróleo ${ }^{151}$. La razón principal de aplicar la legislación nigeriana es asegurar la reparación de acuerdo con las expectativas de la sociedad en la que se produce el daño. Sin embargo, puede que no se consiga el resultado buscado debido a que las leyes de los Estados anfitriones, donde los daños generalmente tienen lugar, son en muchas ocasiones menos estrictas y más tolerantes respecto a los daños ambientales. Por su parte, JÄGERS y VAN DER HEIJDEN señalan que el resultado es que la función preventiva de la responsabilidad civil es empujada a un segundo plano ${ }^{152}$.

\footnotetext{
146 JÄGERS, N.M.C.P. y VAN DER HEIJDEN, M. J., “Corporate...” cit., p. 851.

${ }^{147}$ Véase artículo 6 del Act of 11th April 2001 on Conflicts of Law in Tort.

${ }^{148}$ CASTERMANS, A.G. y VAN DER WEIDE, J. (2010, 17 de junio), “The legal...” cit., p. 51

149 Ídem.

${ }^{150}$ Véase artículo 3.2 del Act of 11th April 2001 on Conflicts of Law in Tort.

${ }^{151}$ Véase párrafo 4.9 de la Sentencia del Tribunal de Distrito de La Haya de 30 de enero de 2013.

152 JÄGERS, N.M.C.P. y VAN DER HEIJDEN, M. J., “Corporate...” cit., p. 851.
} 
Hay algunas excepciones a la aplicación del principio de la lex loci delicti en el sistema legal holandés. Por ejemplo, cuando el demandado y el demandante tienen su residencia principal en el Estado donde se produjo el daño, el caso se regirá por la ley de ese Estado; o cuando el hecho ilícito está estrechamente vinculado con una relación contractual entre las partes, el tribunal puede decidir que la ley que rija el caso sea la que regule la obligación contractual ${ }^{153}$. En el caso de estudio, el tribunal holandés señaló algunas excepciones al principio de lex loci delicti ${ }^{154}$. En primer lugar, de conformidad con el artículo 10:06 del Código Civil holandés, el derecho nigeriano no se aplicaría si esta ley, en este caso específico, fuera incompatible con el orden público holandés ${ }^{155}$; y, en segundo lugar, en caso de prelación de la legislación holandesa de acuerdo con lo establecido en el artículo 10:07 del Código Civil holandés ${ }^{156}$. Sin embargo, según el tribunal, ninguna de las excepciones se ha demostrado o manifestado en el caso. Además, permanece abierta la cuestión sobre en qué casos que afecten a una empresa domiciliada en Holanda por daños en el extranjero se aplicaría la ley de este país. Hasta la fecha, no hay precedente legal en el que se aplique la legislación holandesa en casos de daños ambientales o violaciones de derechos humanos causados por la empresa matriz holandesa o su filial en un Estado tercero ${ }^{157}$.

No obstante, es importante destacar que la entrada en vigor del Reglamento Roma II en 2009 hace viable la aplicación de la legislación holandesa en casos relacionados con daños ambientales. En el caso hipotético de que la legislación holandesa se hubiera aplicado al caso de estudio, el tribunal habría llevado la evaluación sustantiva conforme a la Ley de Responsabilidad Civil (Tort law) holandesa que se aplica a los casos de daños ambientales causados por una empresa holandesa. En Holanda, un daño se comete por: 1) un acto u omisión que viole una obligación legal; 2) violación de un derecho; o 3) una acción u omisión que viole una regla no escrita del deber de cuidado $^{158}$. En el mismo sentido, en relación con los casos de daños ambientales, VAN DER HEIJDEN señala que, de conformidad con el artículo 7 del Reglamento Roma II, la provisión holandesa de responsabilidad ambiental objetiva podría ser aplicable al

\footnotetext{
${ }^{153}$ Véase artículo 5 del Act of 11th April 2001 on Conflicts of Law in Tort.

${ }^{154}$ Véase párrafo 4.9 de la Sentencia del Tribunal de Distrito de La Haya de 30 de enero de 2013.

${ }^{155}$ Véase artículo 10.6 del Código Civil holandés.

${ }^{156}$ Véase artículo 10.7 ibídem.

${ }^{157}$ GARCÍA ÁLVAREZ, L., “Daños...” cit., p. 570.

${ }^{158}$ Véase artículo 6:162 del Código Civil holandés.
} 
caso de estudio ${ }^{159}$. Según la legislación holandesa, la persona que en su práctica profesional o negocio utilice o mantenga bajo su control una sustancia que por sus características pudiera causar daño de carácter grave a las personas o bienes será responsable si este se produce ${ }^{160}$. La autora señala que la disposición contenida en el artículo 6:175 del Código Civil holandés se aplica a casos de contaminación de tierra, agua o aire que sean consecuencia de vertidos de petróleo. Sin embargo, según la autora, si se aplicara la legislación holandesa, la multinacional podría argumentar que la contaminación o la omisión de una limpieza adecuada de los vertidos en el suelo se deben a los conflictos armados, las insurrecciones y/o los disturbios en Nigeria ${ }^{161}$, lo que podría exonerar a la empresa de cualquier responsabilidad basada en el artículo $6: 175^{162}$

En resumen, bajo el régimen de Roma II las víctimas pueden optar por la legislación aplicable en casos relacionados con daños ambientales. Por consiguiente, las víctimas pueden elegir la ley más favorable para el caso en cuestión; por ejemplo, la legislación holandesa, que podría ofrecer mejores condiciones para el litigio en contra de las empresas multinacionales. Sin embargo, hasta ahora no ha habido ningún caso en virtud de la disposición del artículo 7 del Reglamento Roma II que permita a las víctimas del daño ambiental causado por las actividades de las multinacionales elegir la legislación de un Estado miembro de la Unión Europea.

\subsection{Aspectos relevantes en la sentencia definitiva del caso Ducth Shell Nigeria}

Además de lo anteriormente analizado (competencia judicial y ley aplicable) de la sentencia del caso Dutch Shell Nigeria, hay algunas consideraciones en la sentencia definitiva del 30 de enero de 2013 a tener en cuenta. En dicha sentencia, el tribunal holandés sostuvo la responsabilidad civil de la filial Shell Development Company Petroleum por un daño específico causado por negligencia contra Akpan al no asegurar el pozo IBIBIO-I con el fin de evitar sabotaje, lo que conllevó los vertidos ocurridos en 2006 y 2007 cerca de Ikot Ada Udo ${ }^{163}$. Por una parte, en relación con el vertido de

\footnotetext{
${ }^{159}$ VAN DER HEIJDEN, M. J., Transnational... cit., pp. 249-251.

${ }^{160}$ Véase artículo 6:175 del Código Civil holandés.

${ }^{161}$ Véase artículo 6:178 del Código Civil holandés.

${ }^{162}$ VAN DER HEIJDEN, M. J., Transnational... cit., p. 251.

${ }^{163}$ Véase párrafo 5.1 de la Sentencia del Tribunal de Distrito de La Haya de 30 de enero de 2013.
} 
2006, el tribunal señaló que este no fue de gran envergadura y, por otra, respecto al vertido de 2007, con mayores consecuencias, afirmó que se podría haber evitado si la empresa hubiera tomado las medidas adecuadas para evitar el sabotaje. Cabe destacar que la legislación nigeriana establece que el operador de un oleoducto no se hace responsable por los daños resultantes de los vertidos causados por sabotaje. No obstante, el tribunal holandés ordenó a la filial pagar a Akpan los daños y perjuicios causados por la contaminación de hidrocarburos cerca de la comunidad de Ikot Ada Udo. GARCÍA ÁLVAREZ se refiere al fallo del tribunal como "una pequeña victoria, ya que es la primera vez que no sólo se consigue que un tribunal neerlandés reconozca su competencia sobre una empresa extranjera por daños ocurridos en otro Estado, sino también porque se ha conseguido reconocer la responsabilidad de una filial en Nigeria por los daños medioambientales causados por unos vertidos que, con la debida diligencia, podrían haberse evitado a juicio del tribunal" ${ }^{, 164}$.

\section{A. Legitimación de la ONG Milieudefensie}

La legitimación de la ONG Milieudefensie como demandante se adquiere bajo la ficción legal contemplada en el artículo 3:305 (a) del Código Civil holandés. De acuerdo con esta disposición, una fundación o asociación con capacidad jurídica plena que tiene como objeto proteger intereses específicos, según sus estatutos, puede llevar ante los tribunales una demanda para proteger intereses similares de otras personas ${ }^{165}$. De acuerdo con la empresa multinacional, las alegaciones de Milieudefensie en el litigio principal eran inadmisibles debido a que: 1) la disposición del artículo 3:305(a) forma parte del derecho sustantivo holandés, mientras que la legislación nigeriana, aplicable al caso, no reconoce las acciones colectivas (class actions) ${ }^{166}$; y 2) la acción colectiva llevada a cabo por la ONG no ofrece ninguna ventaja a los propios interesados. El tribunal holandés rechazó las alegaciones de la empresa reafirmando la sentencia interlocutoria del 14 de septiembre de 2011, la cual legitima a la ONG como demandante y señala que los requisitos establecidos por el artículo 3:305 del Código Civil holandés se habían cumplido en el presente caso ${ }^{167}$. Asimismo, el tribunal afirmó

\footnotetext{
${ }^{164}$ GARCÍA ÁLVAREZ, L., “Daños...” cit., p. 573.

${ }^{165}$ Véase artículo 3:305 (a) del Código Civil holandés.

${ }^{166}$ Véase párrafo 4.11 de la Sentencia del Tribunal de Distrito de La Haya de 30 de enero de 2013. 167 Ídem.
} 
que las reclamaciones de la ONG van más allá del interés particular de una persona (Akpan), ya que la recuperación de los suelos, la limpieza de los estanques de peces, la purificación de las fuentes de agua y el plan de contingencia para los futuros vertidos de petróleo beneficiarían a la comunidad y al medio ambiente en las proximidades de Ikot Ada $\mathrm{Udo}^{168}$. Además, consideró que las campañas llevadas a cabo por la ONG con el fín de evitar la contaminación del medio ambiente derivada de la extracción de petróleo en Nigeria es una actividad objetiva que Milieudefensie desarrolla para promover los intereses ambientales en Nigeria ${ }^{169}$. Esta consideración reconoce el papel relevante de las $\mathrm{ONG}$ en cuestiones relacionadas con intereses colectivos como el medio ambiente. En casos relacionados con cuestiones medioambientales, las ONG han mostrado interés en ser parte en el litigio contra las empresas multinacionales, lo que puede beneficiar y ayudar a las víctimas para llevar largos y costosos procedimientos judiciales que difícilmente pueden ser asumidos por los afectados, en comparación con la contraparte (empresa multinacional) ${ }^{170}$.

\section{B. Responsabilidad de la empresa matriz}

El Tribunal de Distrito de La Haya ha dejado la puerta abierta respecto a la posibilidad de responsabilizar a una empresa matriz en la UE por los abusos cometidos por su filial en el extranjero. La responsabilidad de la empresa matriz suscita cuestiones interesantes desde el punto de vista jurídico debido a que podría tener un impacto importante en el ámbito internacional. Sin embargo, de acuerdo con la legislación nigeriana de responsabilidad civil, una empresa matriz puede, bajo ciertas circunstancias, ser responsable de los daños causados a terceros por las actividades de sus filiales sobre la base de un deber de cuidado ${ }^{171}$. Según la ONG, invocando el caso inglés Chandler vs. Cape $\operatorname{PLC}^{172}$, la empresa matriz era consciente de la situación problemática de los vertidos de petróleo en Nigeria, además de interferir y ejercer influencia en las actividades de la filial en Nigeria. A pesar de lo alegado por la ONG, el tribunal señaló

\footnotetext{
${ }^{168}$ Véase párrafo 4.12. de la Sentencia del Tribunal de Distrito de La Haya de 30 de enero de 2013. 169 Ídem.

${ }^{170}$ GARCÍA ÁLVAREZ, L., “Daños...” cit., pp. 557-558.

${ }^{171}$ Véase párrafo 4.26 de la Sentencia del Tribunal de Distrito de La Haya de 30 de enero de 2013.

${ }^{172}$ En el caso Chandler vs. Cape PLC se admite la responsabilidad directa de la empresa matriz, siempre y cuando esta se implique en las operaciones de la filial o ejerza un control de facto sobre ella. Véase Chandler $v$ Cape Plc [2012] EWCA Civ 525 (25 de abril de 2012), de: http://www.bailii.org/ew/cases/EWCA/Civ/2012/525.html.
} 
las situaciones donde la empresa matriz asume el deber de cuidado sobre su filial: i) los negocios de la filial y la matriz son esencialmente los mismos; ii) la matriz tiene más conocimiento —o debería tener más conocimiento - que la filial sobre algún aspecto de seguridad y salud; iii) la matriz sabía o debía haberse dado cuenta de que las condiciones de trabajo en la filial no eran apropiadas; y iv) la matriz sabía o debía haber previsto que la filial o sus empleados confiaban en que ella usaría su conocimiento superior para protegerlos ${ }^{173}$. Al respecto, el tribunal señaló que no se puede equiparar la relación de proximidad entre una empresa matriz y los empleados de su filial que opera en el mismo país con la proximidad entre la empresa matriz de una corporación internacional y las personas que viven cerca de los oleoductos e instalaciones petroleras de sus filiales en otros países. En esta última, la relación es más lejana y difusa, por lo que el tribunal consideró que suponer la existencia de un deber de cuidado de la empresa matriz es mucho menos justo, equitativo y razonable de lo que era en el caso Chandler vs. Cape PLC ${ }^{174}$, menos aún si se tiene en cuenta que los daños provocados en este caso no son causados por la filial, sino por un sabotaje de las instalaciones llevado a cabo por un tercero ${ }^{175}$.

\section{Vulneración de los derechos humanos}

Finalmente, de esta lista no exhaustiva de cuestiones relevantes de la sentencia definitiva del caso Dutch Shell Nigeria ante el tribunal holandés cabe resaltar que este consideró que la negligencia por parte de la empresa a la hora de tomar las medidas necesarias para evitar el sabotaje no da lugar a una violación de derechos humanos. Milieudefensie, aduciendo el caso Gbemre vs. Shell Petroleum Development Company, alegaba que la filial nigeriana era responsable de afectar a la integridad física de Akpan ya que este tenía que vivir en un medio ambiente contaminado. No obstante, según el tribunal, la filial no es culpable por una conducta activa (active conduct), sino por negligencia, en contraste con el caso invocado por la ONG, en el que la empresa había infringido un derecho humano por la quema deliberada de gas durante un largo período (conducta activa). Hasta ahora no existe en la jurisprudencia de Nigeria ningún fallo que reconozca la responsabilidad de una empresa por una negligencia (conducta no activa)

\footnotetext{
${ }^{173}$ Véase párrafo 4.28 de la Sentencia del Tribunal de Distrito de La Haya de 30 de enero de 2013.

${ }^{174}$ Véase párrafo 4.29 ibídem.

${ }^{175}$ GARCÍA ÁlVAREZ, L., “Daños...” cit., p. 576.
} 
que da lugar a una violación de los derechos humanos cometida por terceros ${ }^{176}$. ENNEKING señala que esta consideración es difícil de entender a falta de una explicación más detallada y/o justificación. Además, según la autora, el fallo del tribunal deja preguntas sin responder en relación con la responsabilidad de la empresa $^{177}$.

\section{CONCLUSIONES}

El poder económico, social y político de las empresas multinacionales, adquirido gracias a la globalización económica y a la deslocalización de las actividades empresariales, ha conllevado que empresas como Shell en Nigeria tengan un impacto negativo en los derechos humanos y en el medio ambiente de las poblaciones donde operan. El caso Dutch Shell Nigeria establece un precedente para litigar contra las multinacionales que operan en países en desarrollo; sin embargo, pone al descubierto retos a superar en el futuro con el fin de garantizar el acceso a la justicia para las víctimas, especialmente en un contexto de asimetría de poderes, liberalización económica, delimitada competencia internacional de los tribunales, falta de personalidad internacional de las empresas y ausencia de soluciones judiciales efectivas contra estos agentes económicos. Las diversas acciones emprendidas ante diferentes instancias por la conducta irresponsable de la empresa Shell en Nigeria reflejan estos retos.

A nivel internacional, a pesar de la existencia de normas positivas de protección de los derechos humanos y del medio ambiente, estas carecen de efecto directo para la empresa por falta de plena personalidad internacional; asimismo, existe una renuencia de responsabilizar directamente a las empresas por el incumplimiento de normas internacionales, por lo que las acciones en el ámbito internacional recaen principalmente en la falta de debida diligencia del Estado sobre las actividades dentro de su territorio. A nivel nacional, el poder de la empresa multinacional y la dependencia del Estado anfitrión respecto a la inversión extranjera socavan las vías legales para compensar a las víctimas por los daños sufridos por las operaciones de las empresas.

\footnotetext{
${ }^{176}$ Ibídem, pp. 579-580.

${ }^{177}$ ENNEKING, L. (a), “The Future...” cit., p. 52.
} 
Por su parte, el caso Dutch Shell Nigeria ante el tribunal holandés se establece como referencia para los litigios transnacionales en la Unión Europea contra las multinacionales que operan en países en desarrollo. El litigio planteado en Holanda contra la empresa matriz y su filial, además de destacar la falta de homogeneidad en las normas de la Unión Europea respecto a la competencia de los tribunales de los Estados miembros sobre reclamaciones más allá de sus fronteras - cuestión que habría que plantearse en la comunidad internacional en respuesta a la gran cantidad de casos relacionados con empresas multinacionales-, también establece los pasos a seguir en el futuro para este tipo de acciones, que están marcadas por la tendencia internacional de exigir la responsabilidad de las empresas matrices junto con sus filiales en el país de origen debido a que la infraestructura legal de estos países suele ofrecer una justicia más rápida y segura que la de los países en vías de desarrollo, donde suelen tener sus operaciones.

Del caso Dutch Shell Nigeria se debe destacar la necesidad de más y mejores instrumentos y mecanismos legales en diversos ámbitos del derecho que permitan una mayor seguridad jurídica y un mayor equilibrio en las relaciones entre las empresas y las posibles víctimas de daños ambientales para que ni la ubicación geográfica ni la nacionalidad sean condicionantes para alcanzar la justicia ambiental.

\section{VI.BIBLIOGRAFÍA}

AUGENSTEIN, D. (2011, 26 de septiembre), "The Human Rights Dimension of Environmental Protection in EU External Relations Post-Lisbon". Consultado el 5 de abril de 2014, de: http://ssrn.com/abstract=1933675.

AMNISTÍA INTERNACIONAL, Nigeria: Petróleo, contaminación y pobreza en el Delta del Níger, Amnistía internacional, Londres, 2009.

BECERRA RAMÍREZ, M., Panorama del Derecho Mexicano. Derecho Internacional Público, McGraw-Hill, México, DF, 1997.

BORRÁS PENTINAT, S. y VILASECA BOIXAREU, I., "Los conflictos ambientales causados por empresas transnacionales: realidades y retos jurídicos Internacionales”, en Soares Stersi dos Santos, R. y Annoni, D. (coord.), Cooperaçao e conflictos Internacionais: Globalizaçao, Regionalismo e Atores, Curitiba, Multideia, 2014.

CASTERMANS, A.G. y VAN DER WEIDE, J. (2010, 17 de junio), “The legal liability of Dutch parent companies for subsidiaries' involvement in violations of fundamental, 
internationally recognised rights". Consultado el 8 de abril 2014, de: http://ssrn.com/abstract=1626225.

CÉSPEDES-BÁEZ, L. M., "Derechos humanos y responsabilidad de las personas jurídicas privadas: Una tarea pendiente", Revista de la Fundación para el Debido Proceso, vol. 4 núm. 15, 2011.

COMMITTEE ON THE NIGER DELTA (2008, 8 de septiembre), "Report of the Technical Committee on the Niger Delta", volumen 1.

CRUZ CARDOZO, A. P., Análisis de la presencia de petroleras occidentales y la agudización de conflictos político-económicos en el delta del Níger. Caso: la Royal Dutch Shell y el Movimiento para la Emancipación del Delta del Níger (MEND) 20062010, Universidad Colegio Mayor de Nuestra Señora del Rosario, Bogotá, 2011.

EBEGBULEM, J. C., EKPE, D. y ADEJUMO, T. O., "Oil Exploration and Poverty in the Niger Delta Region of Nigeria: A Critical Analysis", International Journal of Business and Social Science, vol. 4, núm. 3, 2013.

ENNEKING, L. (a), "The Future of Foreign Direct Liability? Exploring the International Relevance of the Dutch Shell Nigeria Case", Utrecht Law Review, vol. 10, núm. 1, 2014.

ENNEKING, L. (b), Foreign direct liability and beyond. Exploring the role of tort law in promoting international corporate social responsibility and accountability, Eleven International Publishing, La Haya, 2012.

EWEJE, G., "Environmental Costs and Responsabilities Resulting from Oil Exploitation in Developing Countries: The Case of The Niger Delta of Nigeria", Journal of Business Ethic, vol. 69, núm. 1, 2006.

FRANCIS, P., LAPIN, D. y ROSSIASCO, P., Securing Development and Peace in the Niger Delta. A Social and Conflict Analysis for Change, Woodrow Wilson International Center for Scholars Africa Program, Washington DC, 2011.

FRYNAS, G., "Social and environmental litigation against transnational firms in Africa”, Journal of Modern African Studies, vol. 42, núm. 3, 2004.

GARCÍA ÁLVAREZ, L., "Daños privados por contaminación en el tráfico externo: A propósito del caso Akpan vs. Shell (Nigeria)", Cuadernos de Derecho Transnacional, vol. 5, núm. 2. 2013.

HIIK, Conflict Barometer 2013, HIIK, Heidelberg, 2014. 
HRW (1999, enero), "The Price of Oil: Corporate Responsibility and Human Rights Violations in Nigeria's Oil Producing Communities". Consultado el 2 de abril de 2014, de: http://www.hrw.org/reports/1999/nigeria/nigeria0199.pdf.

ICJ, Access to Justice: Human Rights Abuses Involving Corporations - The Netherlands, ICJ, Ginebra, 2010.

JÄGERS, N., JESSE, K. y VERSCHUUREN, J., “The Future of Corporate Liability for Extraterritorial Human Rights Abuses: The Dutch Case against Shell”, American Journal of International Law, vol. 4, núm. 197, 2013.

JÄGERS, N.M.C.P. y VAN DER HEIJDEN, M.J., "Corporate Human Rights Violations: The Feasibility of Civil Recourse in The Netherlands", Brooklyn Journal of International Law, vol. 33, núm. 3, 2008.

JOHNS, F., "The invisibility of the Transnational Corporations: An Analysis of International Law and Legal Theory", Melbourne University Law Review, vol. 19, 1993-1994.

LOZANO CONTRERAS, J. F., La noción de debida diligencia en Derecho internacional público, Atelier, Barcelona, 2007.

MARTÍNEZ ALIER, J. (2011, 17 de febrero), "El caso Chevron Texaco en Ecuador: una muy buena sentencia que podría ser un poco mejor", ALAI, América Latina en Movimiento, 2011. Consultado el 30 de julio de 2014, de: http://alainet.org/active/44476

MORGERA, E., Corporate accountability in international environmental law, Oxford University Press, Nueva York, 2009.

OKOKO, K., "Shell Petroleum Development Company (S.P.D.C.) - Host Community Relation Study", en Ebegbulem, J. C., Ekpe, D. y Adejumo, T. O., "Oil Exploration and Poverty in the Niger Delta Region of Nigeria: A Critical Analysis", International Journal of Business and Social Science, vol. 4, núm. 3, 2013.

ORELlANA, M., Derechos Humanos y Ambiente: Desafios para el Sistema Interamericano de Derechos Humanos, Center for International Environmental Law CIEL, Washington, 2007.

OTERO GARCÍA-CASTRILLÓN, C., "EL DIPr de la UE en la determinación de la responsabilidad civil por daños al medio ambiente", Anuario Hispano-Luso-Americano de Derecho Internacional, 2013-2014. 
PEÑA GUTIÉRREZ, D., "Responsabilidad Social Corporativa", en Zubizarrea Hernández, J., González, E. y Ramiro, P., Diccionario crítico de empresas transnacionales. Claves para enfrentar el poder de las grandes corporaciones, Icaria, Barcelona, 2012.

PIGRAU, A. y CARDESA-SALZMANN, A., "Acciones entrelazadas contra daños ambientales graves: el impacto e Shell en Nigeria", Revista de la Facultad de Derecho PUCP, núm. 70, 2013.

PIGRAU, A., BORRÀS, S., JARIA, J. y CARDESA-SALZMANN, A., "The Interplay of National, Transnational and International Litigation for Environmental Justice: Seeking Effective Means of Redress for Grave Environmental Damage", ISEE Conference 2012 - Ecological Economics and Rio+20: Challenges and Contributions for a Green Economy, Río de Janeiro (Brasil).

PIGRAU SOLÉ, A., "La responsabilidad internacional de los Estados por daños al medio ambiente", en Sindico, F., Fernández Egea, M. y Borràs Pentinat, S. (eds), Derecho internacional del medio ambiente: Una visión desde Iberoamérica, Cameron May-CMP Publishing Ltd., Londres, 2011.

REQUEJO ISIDRO, M., "Responsabilidad civil y derechos humanos en EEUU: ¿el fin del ATS?”, InDret Revista para el Análisis del Derecho, núm. 3, 2011.

STEINER, R., Double Standar. Shell practices in Nigeria Compared With International Standard to Prevent and Control Pipeline oil Spills and the Deepwater Horizon Oil Spill, Friends of the Earth Netherlands, Ámsterdam, 2010.

TUNDE, O. I. y TANSHI, I., "Ecological Restoration Of Oil Spill Sites in The Niger Delta, Nigeria”, Journal of Sustainable Development in Africa, vol. 11, núm. 2, 2009.

UICN et ál. (2006, 31 de mayo), "Niger Delta Natural Resources Damage Assessment and Restoration Project Phase I Scoping Report”.

UNEP, Environmental Assessment of Ogoniland, UNEP, Nairobi, 2011.

US ENERGY INFORMATION ADMINISTRATION (EIA) (2013, 30 de diciembre), Nigeria.

VAN DER HEIJDEN, M. J., Transnational Corporations and Human Rights Liabilities. Linking Standards of International Public Law to National Civil Litigation Procedures, Intersentia, Amberes, 2012.

WESCHKA, M., "Human Rights and Multinational Enterprises: How Can Multinational Enterprises Be Held Responsible for Human Rights Violations 
Committed Abroad?", Zeitschrift für ausländisches öffentliches Recht und Völkerrecht, núm. 66, 2006.

WRM, "Nigeria: la quema de gas, contribuye al cambio climático y a la violación de los derechos humanos", Boletín Movimiento por los Bosques Tropicales, núm. 136, noviembre de 2008.

WURTHMANN, G., "Ways of Using the African Oil Boom for Sustainable Development", Economic Research Working Paper Series, núm. 84, 2006.

ZERK, J. A., "Extraterritorial Jurisdiction: Lessons for the Business and Human Rights sphere from six regulatory areas", Corporate Social Responsibility Initiative Working Paper, núm. 59, 1 de junio de 2010. 